\title{
Sustained Systemic Glucocerebrosidase Inhibition Induces Brain $\alpha$-Synuclein Aggregation, Microglia and Complement C1q Activation in Mice
}

\author{
Emily M. Rocha, Gaynor A. Smith, Eric Park, ${ }^{2}$ Hongmei Cao, ${ }^{2}$ Anne-Renee Graham,, Eilish Brown, \\ Jesse R. McLean,' Melissa A. Hayes,' Jonathan Beagan,' Sarah C. Izen,' Eduardo Perez-Torres,' \\ Penelope J. Hallett, and Ole Isacson ${ }^{1}$
}

\begin{abstract}
Aims: Loss-of-function mutations in GBA1, which cause the autosomal recessive lysosomal storage disease, Gaucher disease (GD), are also a key genetic risk factor for the $\alpha$-synucleinopathies, including Parkinson's disease (PD) and dementia with Lewy bodies. GBAl encodes for the lysosomal hydrolase glucocerebrosidase and reductions in this enzyme result in the accumulation of the glycolipid substrates glucosylceramide and glucosylsphingosine. Deficits in autophagy and lysosomal degradation pathways likely contribute to the pathological accumulation of $\alpha$ synuclein in PD. In this report we used conduritol- $\beta$-epoxide (CBE), a potent selective irreversible competitive inhibitor of glucocerebrosidase, to model reduced glucocerebrosidase activity in vivo, and tested whether sustained glucocerebrosidase inhibition in mice could induce neuropathological abnormalities including $\alpha$-synucleinopathy, and neurodegeneration. Results: Our data demonstrate that daily systemic CBE treatment over 28 days caused accumulation of insoluble $\alpha$-synuclein aggregates in the substantia nigra, and altered levels of proteins involved in the autophagy lysosomal system. These neuropathological changes were paralleled by widespread neuroinflammation, upregulation of complement $\mathrm{Clq}$, abnormalities in synaptic, axonal transport and cytoskeletal proteins, and neurodegeneration. Innovation: A reduction in brain GCase activity has been linked to sporadic PD and normal aging, and may contribute to the susceptibility of vulnerable neurons to degeneration. This report demonstrates that systemic reduction of GCase activity using chemical inhibition, leads to neuropathological changes in the brain reminiscent of $\alpha$-synucleinopathy. Conclusions: These data reveal a link between reduced glucocerebrosidase and the development of $\alpha$-synucleinopathy and pathophysiological abnormalities in mice, and support the development of GCase therapeutics to reduce $\alpha$-synucleinopathy in PD and related disorders. Antioxid. Redox Signal. 23, 550-564.
\end{abstract}

\section{Introduction}

$\mathbf{T}$ HE $\alpha$-SYNUCLEINOPATHIES are a group of neurodegenerative disorders, which include Parkinson's disease (PD), Lewy body with dementia, and multiple system atrophy. Collectively, these diseases share a common pathology hallmark, accumulation of undegraded $\alpha$-synuclein as the major component of the proteinacious Lewy body inclusions (37). A current challenge in $\alpha$-synucleinopathy research is isolating the mechanism(s) that promote(s) accumulation of toxic $\alpha$-synuclein oligomers and determining how this accumulation contributes to the pathology of these diseases.

A homozygous loss-of-function mutation in GBAl causes the well-characterized lysosomal storage disorder, Gaucher

\footnotetext{
${ }^{1}$ Neuroregeneration Research Institute, Harvard Medical School/McLean Hospital, Belmont, Massachusetts.

${ }^{2}$ Shire, Lexington, Massachusetts.
}

(C) Emily M. Rocha et al. 2015; Published by Mary Ann Liebert, Inc. This Open Access article is distributed under the terms of the Creative Commons Attribution Noncommercial License (http://creativecommons.org/licenses/by-nc/4.0/) which permits any noncommercial use, distribution, and reproduction in any medium, provided the original author(s) and the source are credited. 


\section{Innovation}

A reduction in brain GCase activity has been linked to sporadic PD and normal aging, and may contribute to the susceptibility of vulnerable neurons to degeneration. This report demonstrates that systemic reduction of GCase activity using chemical inhibition, leads to neuropathological changes in the brain reminiscent of $\alpha$-synucleinopathy.

disease (22). Gaucher disease patients typically express less than $15 \%$ of functional glucocerebrosidase (GCase) $(25,62)$, which causes accumulation of glucosylceramide (GluCer) and glucosylsphingosine (GluSph) (22). The initial association between GBA1 mutations and the $\alpha$-synucleinopathies occurred in the clinic when a subset of Gaucher disease patients developed parkinsonian symptoms $(32,42,58,59)$. Moreover, the prevalence of PD was higher in relatives of Gaucher disease patients in comparison with sporadic PD patients who do not have relatives with Gaucher disease $(21,23)$.

To date, $\sim 300$ different GBA1 mutations have been identified, including missense, nonsense, and frameshift mutations, as well as insertions, deletions, and complex alleles $(26,54)$. The majority of these mutations result in a significant loss of lysosomal GCase activity $(39,54)$. Individuals who are heterozygous carriers of a $G B A 1$ mutation that results in a 30$50 \%$ reduction in GCase activity are at an increased risk for developing PD at a frequency of 4-7\% $(3,31,43,61) ; 6-7 \%$ of early-onset PD patients are GBAl mutation carriers (GBA1$\mathrm{PD}$ ), which is not surprising, given that GBA1-PD are associated with more severe cognitive symptoms and increased $\alpha$-synuclein accumulation relative to PD patients who are not GBA1 mutation (nonGBA1-PD) carriers (40, 43, 53, 54). In addition to this genetic association between GBA1 and PD, nonGBA1-PD patients also show a significant reduction in lysosomal GCase, suggesting that GCase levels may be important to the pathophysiology of PD $(19,47)$.

Age-dependent lysosomal dysfunction likely contributes to the onset and progression of the $\alpha$-synucleinopathies by promoting accumulation of oligomeric $\alpha$-synuclein. Aging lysosomes undergo dramatic changes, including impaired volume regulation, accumulation of indigestible materials, and impaired regulation of intralysosomal $\mathrm{pH}$ (35). GCase activity gradually declines with age in the substantia nigra and putamen, eventually becoming comparable with nonGBA1-PD patients (47). This reduction in GCase activity is accompanied by an accumulation of GluSph (47). These agerelated changes may be early indicators of PD.

Deficits in autophagy-lysosomal degradation are implicated in the pathophysiology of PD $(14,40)$. The number of lysosomal-associated membrane protein (LAMP)-1-positive lysosomes is reduced and the macroautophagy-related protein, microtubule-associated protein 1A/1B-light chain 3 (LC3)-II, is elevated in the substantia nigra of PD patients in comparison with age-matched control brains (14). Macroautophagy is the major pathway by which cytoplasmic contents are degraded in the lysosome and this process relies on vesicular trafficking rather than direct import of substrates into lysosomes. Macroautophagy is initiated by the conversion of LC3-I into its lipidated form, LC3-II, initiating the formation of double-layered autophagosomes (27). Mature autophagosomes will engulf cy- toplasmic material tagged with the ubiquitin-like protein, p62/ SQSTM1, transport its contents to the lysosome, fuse with the outer lysosomal membrane, and release its contents for degradation (29). Mice defective in macroautophagy die soon after birth, and conditional knockdown of a macroautophagy-related protein (Atg7) in dopamine neurons causes neurodegeneration and inclusion formation $(1,30)$. GCase null neurons are deficient in autophagy, which correlate with accumulation of p62/ SQSTM1 ubiquitinated proteins, and insoluble $\alpha$-synuclein (45).

Interventions that increase lysosomal GCase may preserve lysosomal function by enhancing autophagy and reducing the progression of the disease. To date, the only known regulator of GCase expression is the transcription factor EB (TFEB), which also regulates autophagy and lysosomal biogenesis $(50,52)$. Overexpression of TFEB or GBA can reduce $\alpha$ synucleinopathy and prevent neurodegeneration in rodent models of $\alpha$-synucleinopathy $(13,48,49)$. As accumulation of toxic $\alpha$-synuclein oligomers is considered to be pathogenic in PD (38), deficits in lysosomal degradation of $\alpha$-synuclein could have a substantial impact on the disease process.

The current article critically tests the hypothesis whether long-term inhibition of GCase can disrupt autophagylysosomal degradation and promote accumulation of $\alpha$ synuclein aggregation in mice. Our data demonstrate that chronic pharmacological inhibition of GCase using the selective inhibitor for lysosomal GCase, conduritol- $\beta$-epoxide (CBE), promotes the accumulation of $\alpha$-synuclein aggregates and neuronal cell death by disrupting lysosomal function and inducing widespread neuroinflammation.

\section{Results}

\section{Chronic CBE treatment inhibited GCase activity} and promoted the accumulation of lipid substrates

Pharmacological inhibition of GCase in mice was achieved using a selective and irreversible competitive inhibitor of GCase, CBE. Mice at 3-4 months of age were injected systemically with $100 \mathrm{mg} / \mathrm{kg}$ of $\mathrm{CBE}$ for 28 consecutive days and euthanized $24 \mathrm{~h}$ later. Chronic CBE treatment significantly blocked GCase activity in the forebrain of mice compared with vehicle treatment $\left(\mathrm{T}_{1,3}=14.09, p<0.05\right.$; Fig. 1A). Inhibition of GCase was paralleled by increased levels of GluCer $\left(\mathrm{T}_{1,8}=5.756, p<0.05\right)$ and GluSph $\left(\mathrm{T}_{1,8}=4.027, p<0.05\right.$; Fig. 1B). To determine whether these outcomes were transient, a separate cohort of mice was injected with $100 \mathrm{mg} / \mathrm{kg}$ of CBE for 28 consecutive days and euthanized $24 \mathrm{~h}, 3$ days, 5 days, or 7 days after the final injection (Fig. 1C). Data indicate that GCase activity remained significantly decreased in the forebrain at $24 \mathrm{~h}, 3$ days, and 5 days $\left(\mathrm{F}_{5,14}=21.8, p<0.05\right)$ and gradually returned to baseline levels by 7 days (Fig. 1C). Similarly, GCase activity remained significantly decreased in the midbrain and cerebellum at $24 \mathrm{~h}$ and 3 days $\left(\mathrm{F}_{5,14}=21.8\right.$, and 18.32, $p<0.05$, respectively) following the last $\mathrm{CBE}$ injection and gradually returned to baseline levels by 5 days (Fig. 1C). In parallel, we measured GluSph levels in these same homogenates and found that GluSph levels were significantly increased in the forebrain at $24 \mathrm{~h}\left(\mathrm{~F}_{5,14}=10.1, p<0.05\right)$ and gradually returned to baseline levels by 3 days following the last $\mathrm{CBE}$ injection (Fig. 1D). Similarly, GluSph levels remained significantly elevated in the midbrain and cerebellum at $24 \mathrm{~h}$ and 3 days $\left(\mathrm{F}_{5,14}=10.1\right.$, and $15.3, p<0.05$, respectively) following the last $\mathrm{CBE}$ injection and returned to baseline levels by 5 days (Fig. 1D). 

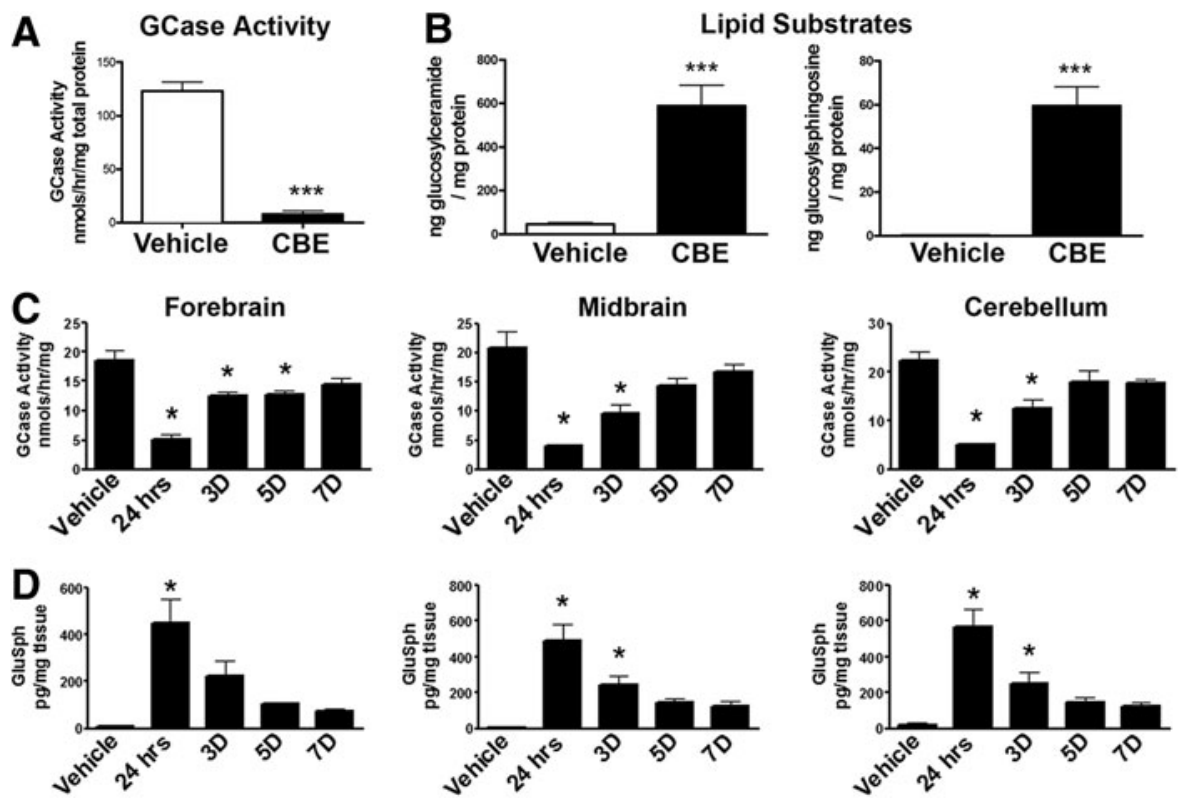

FIG. 1. Chronic conduritol- $\beta$-epoxide (CBE) treatment inhibits glucocerebrosidase (GCase) activity and promotes the accumulation of glucosylceramide (GluCer) and glucosylsphingosine (GluSph). Chronic (28 days) systemic treatment of CBE at $100 \mathrm{mg} / \mathrm{kg}$ in mice inhibits GCase activity in the brain. Data show that CBE blocked GCase activity in forebrain tissue homogenates from CBE-treated mice at $24 \mathrm{~h}$ postfinal CBE injection (A). The same forebrain tissue homogenates were used to determine GluCer and GluSph accumulation by mass spectroscopy chromatography. GluCer and GluSph accumulated in the forebrain following chronic inhibition of GCase by CBE (B). To determine the kinetics of GCase activity recovery and reductions in GluSph levels over time, GCase and GluSph levels were measured at 3,5, and 7 days postchronic (28 days) CBE treatment in the forebrain, midbrain, and cerebellum (C). GCase activity gradually increased and returned to basal levels by 7 days in the forebrain and by 5 days in the midbrain and cerebellum (C). GluSph levels gradually decreased and returned to basal levels by 3 days in the forebrain and 5 days in the midbrain and cerebellum (D). ${ }^{*} p<0.05$, unpaired $t$-test. $n=3-5 /$ group. Graphs are expressed as mean \pm SEM.

A
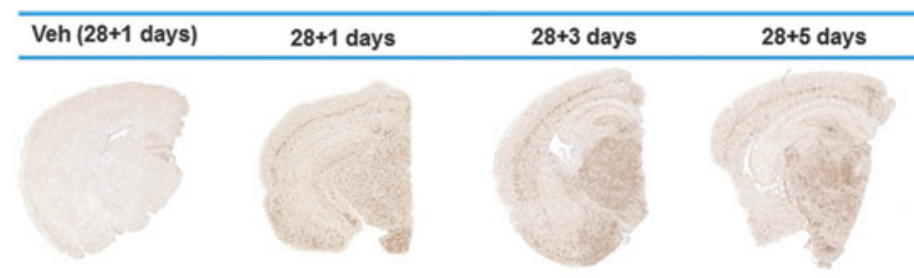

B

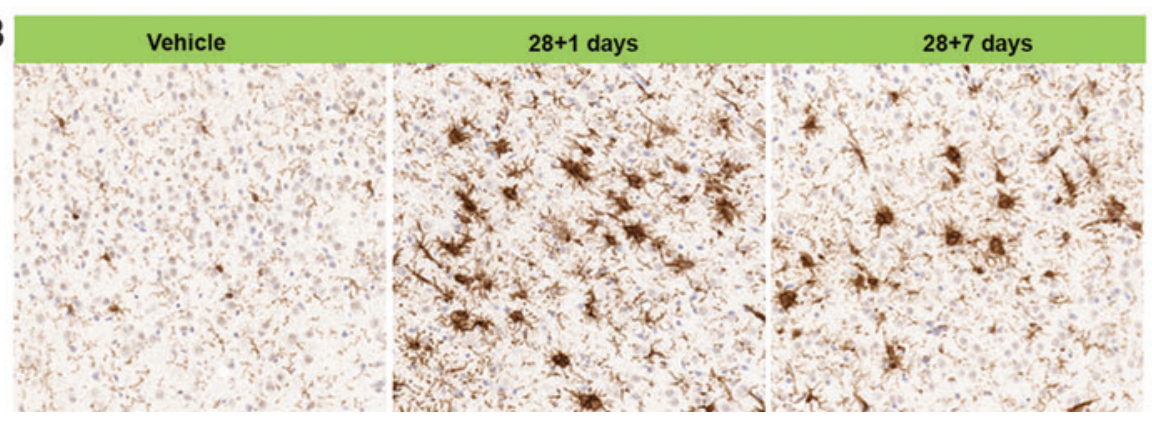

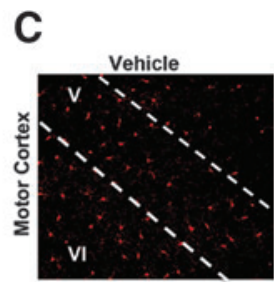
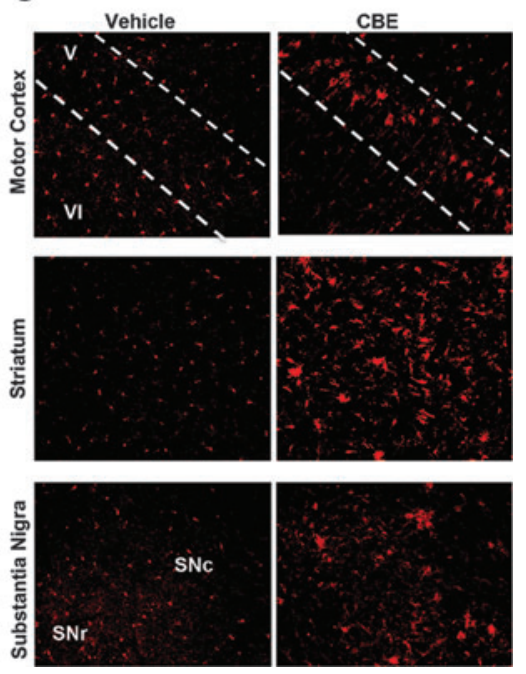

FIG. 2. GCase inhibition induced widespread neuroinflammatory response in mice. Chronic 28-day treatment of CBE $(100 \mathrm{mg} / \mathrm{kg})$ increased the number of Iba-1-positive microglia throughout the brain and these microglia remained highly reactive even 7 days postcessation of CBE (A). CBE caused a distinct microglial response in cortical layer V (A), which can clearly be seen at magnification (B). CBE also caused a microglial response in the striatum and substantia nigra, as evidenced by Iba-1-positive microglial (C). 


\section{GCase inhibition induced widespread}

neuroinflammatory response as well as synaptic, axonal transport, and cytoskeletal changes in mice

We have previously shown that alterations in proteins involved in neuroinflammation, synaptic transmission, axonal transport, and the cytoskeleton precede degeneration of dopamine neurons in the substantia nigra and striatum using an animal model of $\alpha$-synucleinopathy (9). Therefore, we sought to determine whether prolonged inhibition of GCase caused neuroinflammatory, synaptic, cytoskeletal, and axonal transport changes.

Inhibition of GCase for 28 days caused widespread microglial activation that remained elevated for 7 days following cessation of CBE (Fig. 2A, B). Widespread Iba-1-positive reactive microglia were evident throughout the brain, particularly in layer $\mathrm{V}$ of the cortex, as seen with higher magnification (Fig. 2B). Fluorescent staining using Iba-1 clearly illustrated a heightened microglial response in the motor cortex, striatum, and substantia nigra in CBE-treated mice in comparison with vehicle-treated mice (Fig. 2C). It has been suggested that the classical complement pathway, which is activated during de- velopmental synaptic pruning, is reactivated during neurodegenerative diseases and is involved with removal of weak synapses (57). Our data show that chronic inhibition of GCase induced $\mathrm{C} 1 \mathrm{q}$ expression, the first subcomponent of the $\mathrm{C} 1$ complex of the classical complement pathway, in the striatum $\left(\mathrm{T}_{1,6}=2.416, p<0.05\right)$, substantia nigra $\left(\mathrm{T}_{1,8}=6.072, p<0.05\right)$, and motor cortex $\left(\mathrm{T}_{1,6}=3.278, p<0.05\right.$; Fig. 3A).

A large battery of synaptic, axonal transport, and cytoskeletal proteins was investigated in the substantia nigra, striatum, and motor cortex of mice treated with CBE for 28 consecutive days (Figs. 3-5). Chronic inhibition of GCase did not induce changes in protein levels of the SNARE complex-associated protein, SNAP-25, in the striatum, substantia nigra, or motor cortex (Fig. 3B). Levels of synaptophysin were increased in the striatum $\left(\mathrm{T}_{1,8}=2.481, p<0.05\right)$ and did not change in the substantia nigra and motor cortex (Fig. 3C). However, levels of synaptotagmin were significantly decreased in the motor cortex $\left(\mathrm{T}_{1,6}=2.647, p<0.05\right)$, but remained unchanged in the striatum and substantia nigra of mice treated with $\mathrm{CBE}$ (Fig. 3D). Levels of the presynaptic protein, synapsin, were not altered in the striatum, substantia nigra, and motor cortex
A
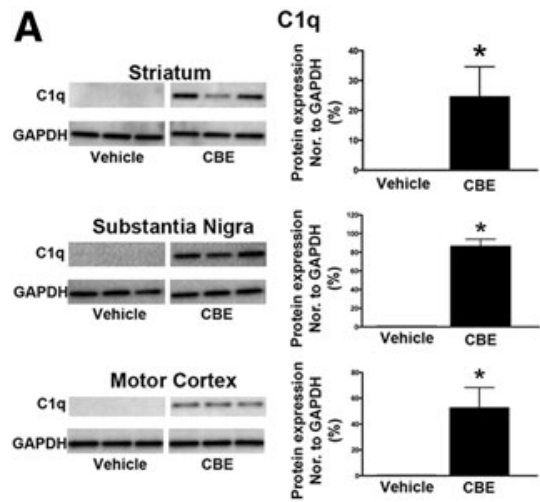

D
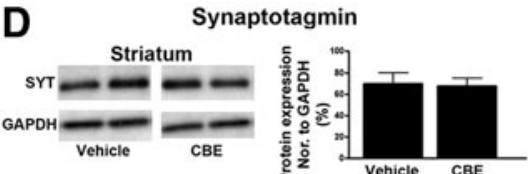

Substantia Nigra
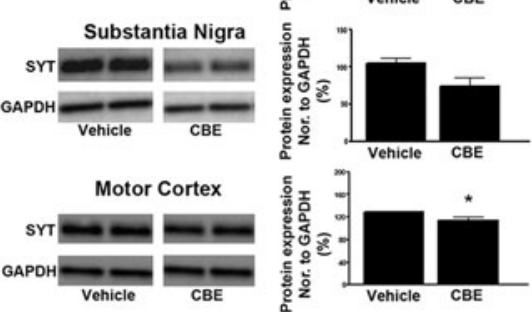

B
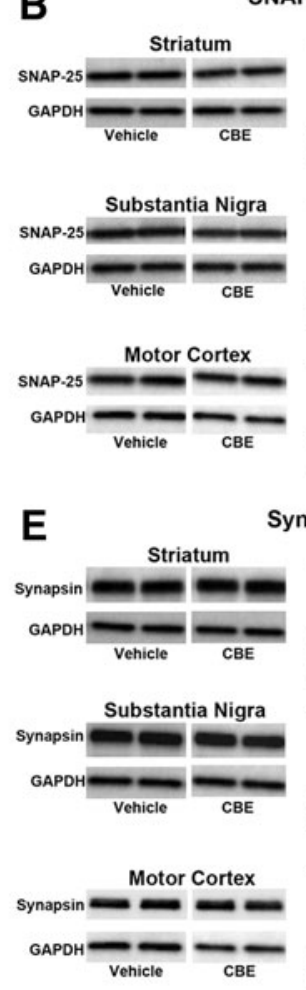
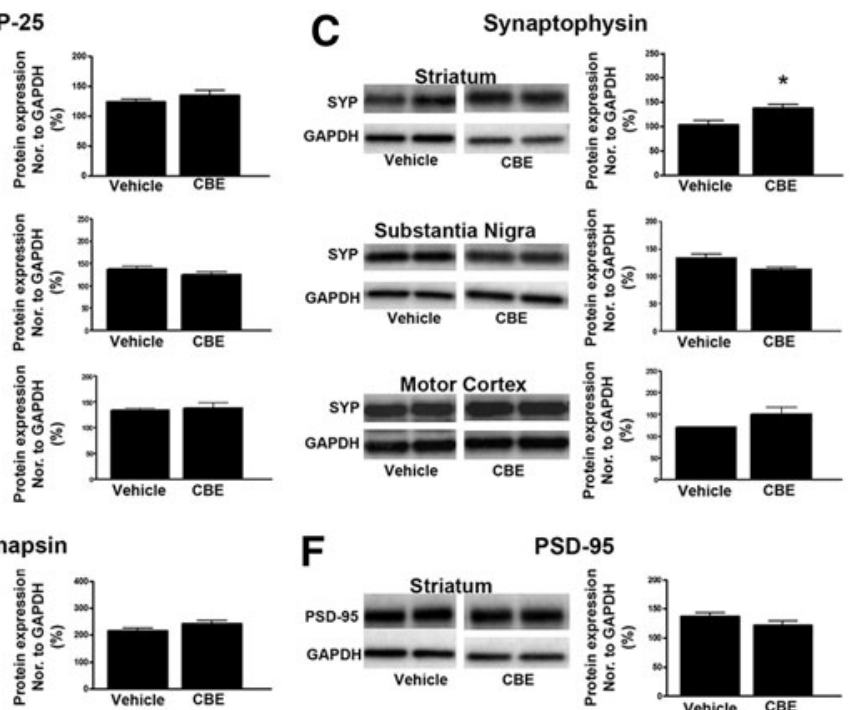

PSD-95
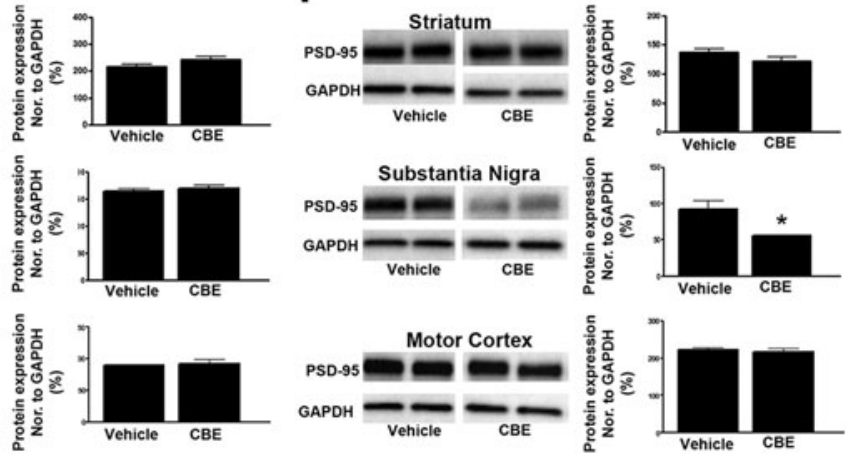

FIG. 3. GCase inhibition resulted in dysregulation of proteins involved in synaptic transmission in mice. Western blots were performed to determine whether chronic 28-day treatment of CBE $(100 \mathrm{mg} / \mathrm{kg})$ altered expression levels of proteins necessary for synaptic transmission. Whole-cell lysates $(20-30 \mu \mathrm{g})$ from the striatum, substantia nigra, and motor cortex were homogenized and processed. The data indicate that $\mathrm{CBE}$ induced the expression of $\mathrm{Clq}$, the initiating protein of the classical complement in the striatum, substantia nigra, and motor cortex (A). Levels of synaptosomal-associated protein 25 (SNAP-25) remained unchanged in the striatum, substantia nigra, and motor cortex following CBE treatment $(\mathbf{B})$. Protein levels of synaptophysin were increased in the striatum and motor cortex in mice treated with $\mathrm{CBE}$. In contrast, synaptophysin was decreased in the substantia nigra of CBEtreated mice (C). Levels of synaptotagmin were decreased in the motor cortex and substantia nigra. Levels of synaptotagmin remained unchanged in the striatum (D). Levels of the presynaptic protein, synapsin, remained unchanged in the striatum, substantia nigra, and motor cortex (E). Levels of the postsynaptic protein, postsynaptic density protein 95 (PSD-95), remain unchanged in the striatum and motor cortex (F). Levels of PSD-95 were decreased in the substantia nigra in mice treated with CBE (F). Optical densities (ODs) of the individual bands were quantified using NIH ImageJ and normalized to glyceraldehyde-3-phosphate dehydrogenase (GAPDH) on the same gel. ${ }^{*} p<0.05$, unpaired t-test. $n=3-5 /$ group. Graphs are expressed as mean \pm SEM. 
A
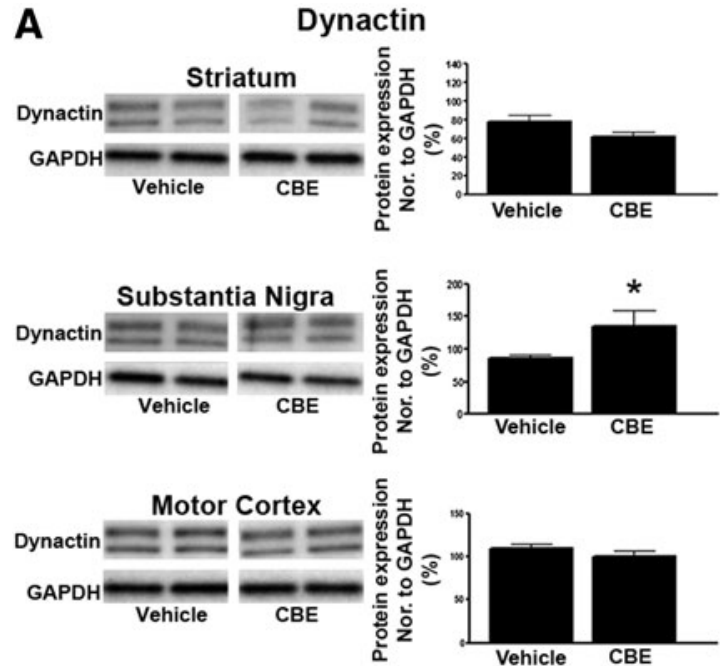

C
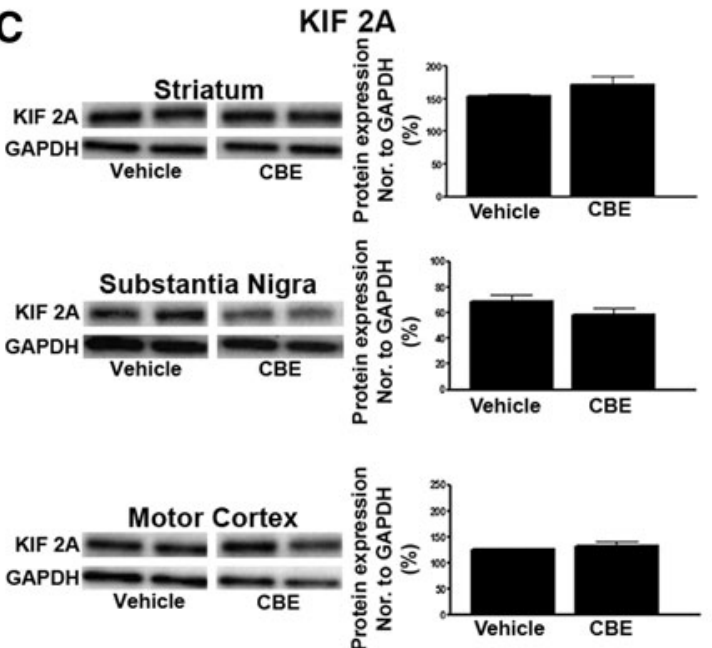

B
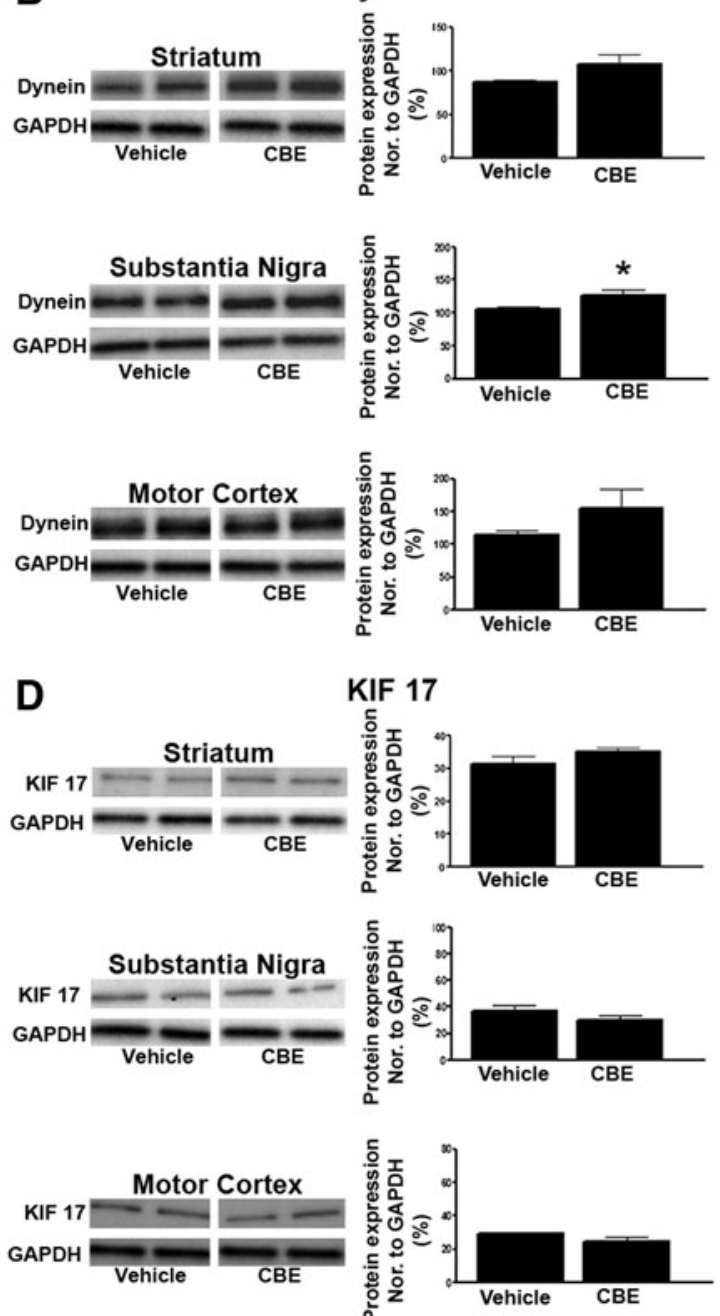

FIG. 4. GCase inhibition caused dysregulation of proteins involved in retrograde transport in mice. Western blots were performed to determine whether chronic 28-day treatment of CBE $(100 \mathrm{mg} / \mathrm{kg})$ altered expression levels of proteins necessary for axonal transport. Whole-cell lysates (20-30 $\mu \mathrm{g})$ from the striatum, substantia nigra, and motor cortex were homogenized and processed. Data indicate that the levels of the retrograde transport proteins, dynactin and dynein, were increased in the substantia nigra of mice treated with CBE (A, B). Levels of the anterograde transport proteins, KIF 2A and KIF 17, remained unchanged in the striatum, substantia nigra, and motor cortex $(\mathbf{C}, \mathbf{D})$. ODs of the individual bands were quantified using NIH ImageJ and normalized to GAPDH on the same gel. * $p<0.05$, two-way ANOVA. $n=3-5 /$ group. Graphs are expressed as mean \pm SEM.

(Fig. 3E). Lastly, levels of postsynaptic density protein 95 (PSD-95) were decreased in the substantia nigra $\left(\mathrm{T}_{1,7}=2.89\right.$, $p<0.05$ ) following CBE treatment (Fig. 3E).

Several retrograde and anterograde transport proteins were also measured to determine if GCase inhibition can disrupt axonal transport. CBE caused an increase in the levels of the retrograde transport proteins, dynactin $\left(\mathrm{T}_{1,6}=2.52, p<0.05\right)$ and dynein $\left(\mathrm{T}_{1,6}=2.532, p<0.05\right)$, in the substantia nigra (Fig. 4A, B). However, levels of dynactin and dynein remained unchanged in striatum and motor cortex. Levels of the anterograde transport proteins, KIF $2 \mathrm{~A}$ and KIF 17, remained unchanged in these three brain regions (Fig. 4C, D).

Three cytoskeletal proteins were also measured to determine if chronic GCase inhibition disrupted the microtubules. The cytoskeletal protein, $\alpha$-tubulin, was significantly decreased in the striatum $\left(\mathrm{T}_{1,6}=2.527, p<0.05\right)$ and increased in the substantia nigra $\left(\mathrm{T}_{1,6}=3.525, p<0.05\right)$ of mice treated with CBE (Fig. 5A). Levels of $\alpha$-tubulin were not altered in the motor cortex following CBE treatment (Fig. 5A). Protein levels of $\beta$-tubulin were decreased in the substantia nigra $\left(\mathrm{T}_{1,6}=5.665, p<0.05\right)$ of mice treated with CBE and remained unchanged in the striatum and motor cortex (Fig. 5B). Finally, levels of $\gamma$-tubulin were not altered in mice treated with CBE in any region studied (Fig. 5C).

\section{GCase inhibition caused accumulation of proteinase- $K$-resistant insoluble $\alpha$-synuclein aggregates and induced autophagy-lysosomal proteins}

Immunohistochemistry was used to determine if chronic inhibition of GCase could cause the accumulation of insoluble $\alpha$-synuclein aggregates. The number and size of the $\alpha$ synuclein aggregates were quantified in the substantia nigra of mice $24 \mathrm{~h}$ after the final treatment of CBE (Fig. 6A). There was a significant increase, $\sim 25$-fold, in the number of proteinase$\mathrm{K}$ resistant $\alpha$-synuclein aggregates between 1 and $10 \mu \mathrm{m}^{2}$ 
A
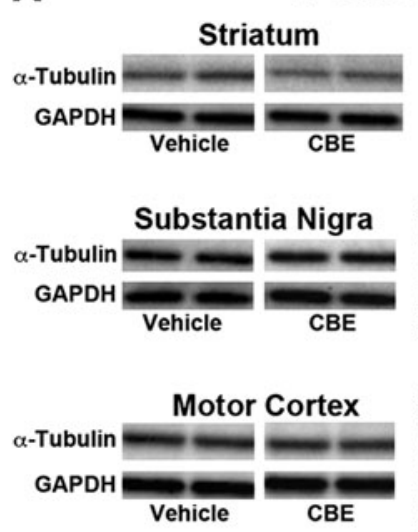
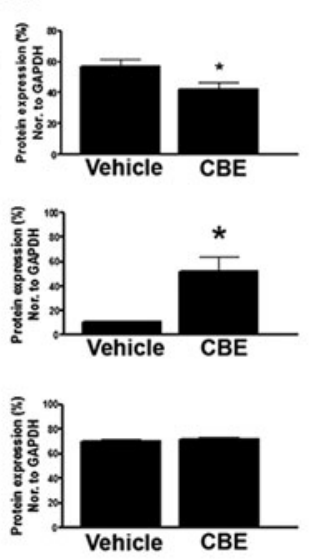

B
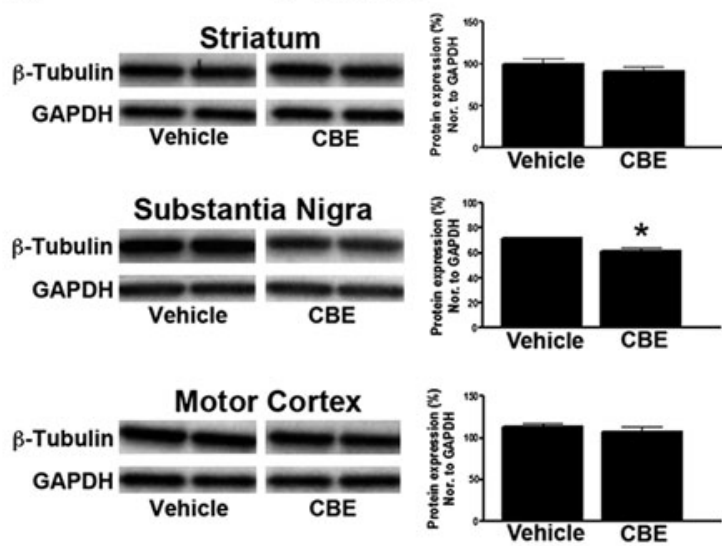

C $\gamma$-Tubulin
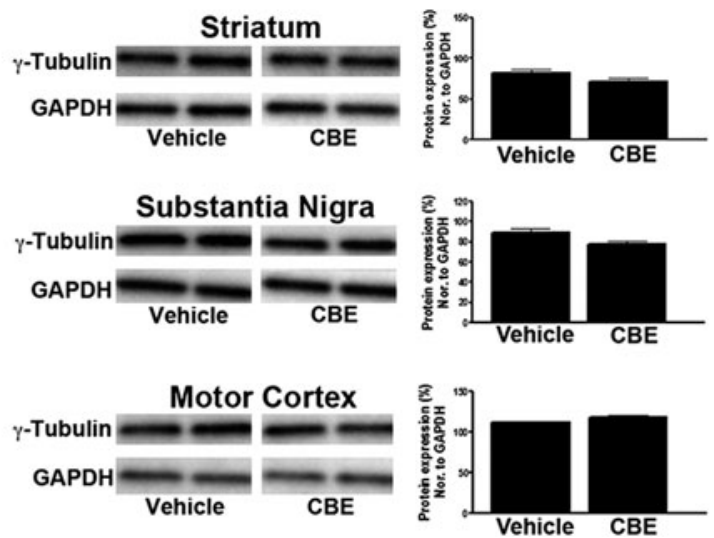

FIG. 5. GCase inhibition induced altered protein levels of cytoskeletal proteins in mice. Western blots were performed to determine whether chronic 28-day treatment of CBE $(100 \mathrm{mg} / \mathrm{kg})$ altered expression levels of cytoskeletal proteins. Whole tissue lysates $(20-30 \mu \mathrm{g})$ from the striatum, substantia nigra, and motor cortex were homogenized and processed. Data indicate that levels of the cytoskeletal protein, $\alpha$-tubulin, were decreased in the striatum and increased in the substantia nigra following CBE treatment (A). Levels of $\alpha$-tubulin remained unchanged in the motor cortex (A). Levels of $\beta$-tubulin were decreased in the substantia nigra; however, they remained unchanged in the striatum and motor cortex (B). Levels of $\gamma$-tubulin remained unchanged following chronic CBE treatment (C). ODs of the individual bands were quantified using NIH ImageJ and normalized to GAPDH on the same gel. ${ }^{*} p<0.05$, unpaired $t$-test. $n=3-5 /$ group. Graphs are expressed as mean \pm SEM.

$\left(\mathrm{T}_{1,5}=3.034, p<0.05\right)$, a 6 -fold increase in the number of aggregates between 11 and $20 \mu \mathrm{m}^{2}\left(\mathrm{~T}_{1,5}=2.75, p<0.05\right)$, a 10fold increase in the number of aggregates between 21 and $50 \mu \mathrm{m}^{2}\left(\mathrm{~T}_{1,5}=2.73, p<0.05\right)$, a 3 -fold increase in the number of aggregates between 51 and $150 \mu \mathrm{m}^{2}\left(\mathrm{~T}_{1,5}=3.076, p<0.05\right)$, and finally a 2 -fold increase in the number of aggregates over $>151 \mu \mathrm{m}^{2}\left(\mathrm{~T}_{1,5}=8.6, p<0.05\right.$; Fig. $\left.6 \mathrm{~A}\right)$.

We chose to measure specific proteins involved in chaperonemediated autophagy (CMA; LAMP-2A) and macroautophagy (LC3-I/II and SQSTM1/p62) following GCase inhibition. The lysosomal protease, cathepsin $\mathrm{D}$, has also been reported to be necessary for $\alpha$-synuclein degradation (12); therefore, we measured whether inhibition of GCase by CBE altered levels of cathepsin D. Chronic 28-day dosing of CBE increased the expression of LAMP-2A in the substantia nigra $\left(\mathrm{T}_{1,6}=6.313\right.$, $p<0.05)$, striatum $\left(\mathrm{T}_{1,6}=2.723, p<0.05\right)$, and motor cortex $\left(\mathrm{T}_{1,6}=7.805, p<0.05\right)$ compared with vehicle treatment (Fig. 6B). CBE also increased the expression of the lipidated form of LC3 (LC3-II) in the substantia nigra $\left(\mathrm{T}_{1,6}=3.182, p<0.05\right)$, striatum $\left(\mathrm{T}_{1,6}=2.73, p<0.05\right)$, and motor cortex $\left(\mathrm{T}_{1,6}=3.580\right.$, $p<0.05)$ of CBE-treated mice compared with vehicle treatment
(Fig. 6C). Similarly, levels of cathepsin D were increased in the substantia nigra $\left(\mathrm{T}_{1,6}=3.525, p<0.05\right)$, striatum $\left(\mathrm{T}_{1,6}=3.56\right.$, $p<0.05)$, and motor cortex $\left(\mathrm{T}_{1,6}=3.921, p<0.05\right)$ of mice treated with CBE compared with vehicle treatment (Fig. 6D). Lastly, we examined levels of the ubiquitin-like protein, p62/ SQSTM1, and despite the modest increase in SQSTM1/p62 within the substantia nigra and striatum, it did not reach statistical significance compared with vehicle treatment (Fig. 6E).

\section{Inhibition of GCase induced cortical cell loss in mice}

Stereological cell counts were conducted in the cortex of mice treated with $\mathrm{CBE}$ and revealed that chronic inhibition of GCase induced neuronal cell loss in the motor and somatosensory cortices. CBE induced a significant reduction in the number of NeuN-positive neurons in layer $\mathrm{V}\left(\mathrm{T}_{1,5}=7.315\right.$, $p<0.05)$ and layer VI $\left(\mathrm{T}_{1,5}=4.951, p<0.05\right)$ of the motor cortex in comparison with vehicle-treated mice (Fig. 7A). Similarly, CBE induced a significant reduction in the number of NeuN-positive neurons in layer $\mathrm{V}\left(\mathrm{T}_{1,5}=2.845, p<0.05\right)$ and layer VI $\left(\mathrm{T}_{1,5}=3.038, p<0.05\right)$ of the somatosensory 
A

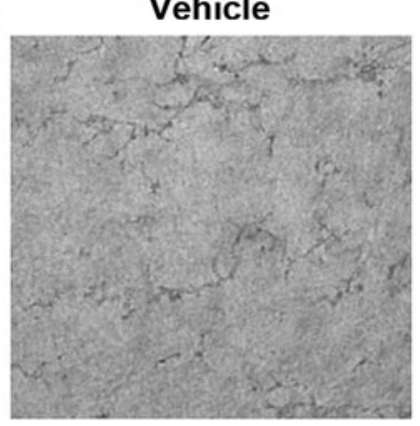

Substantia Nigra: Proteinase-K insoluble $\alpha$-synuclein aggregates

CBE

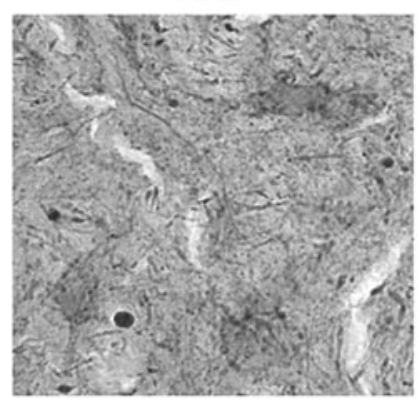

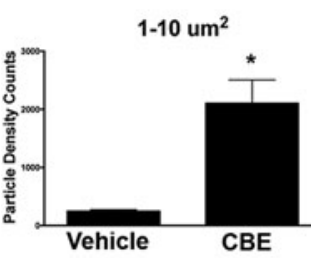

B

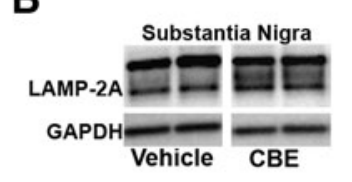

LAMP-2A
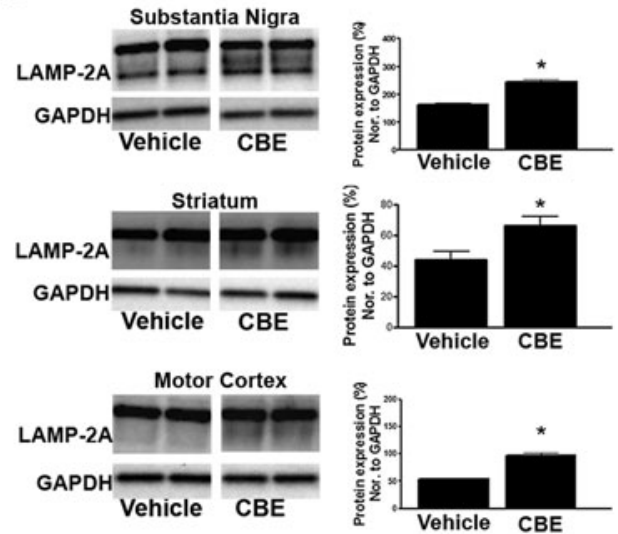

D

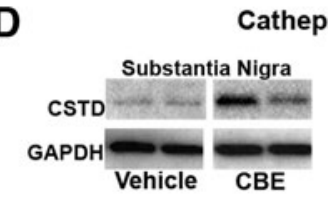

Cathepsin D
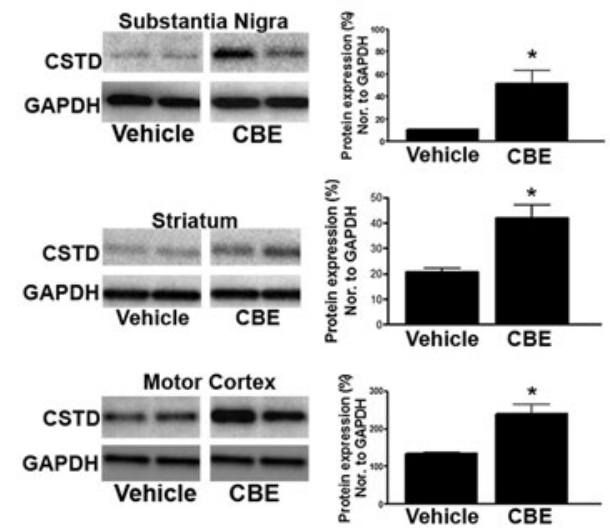
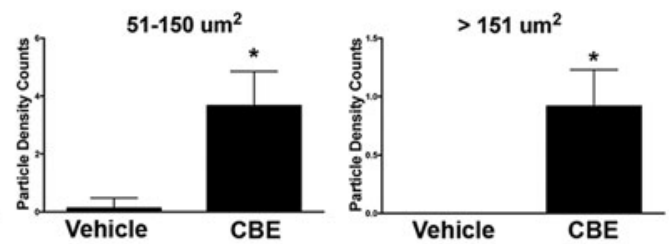

LC3 I/II
C
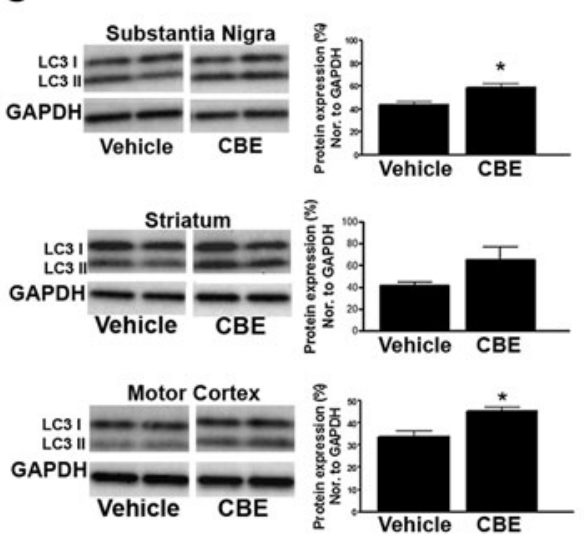

E

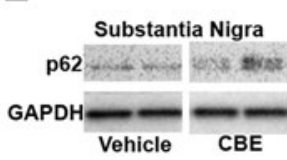

SQSTM1 / p62
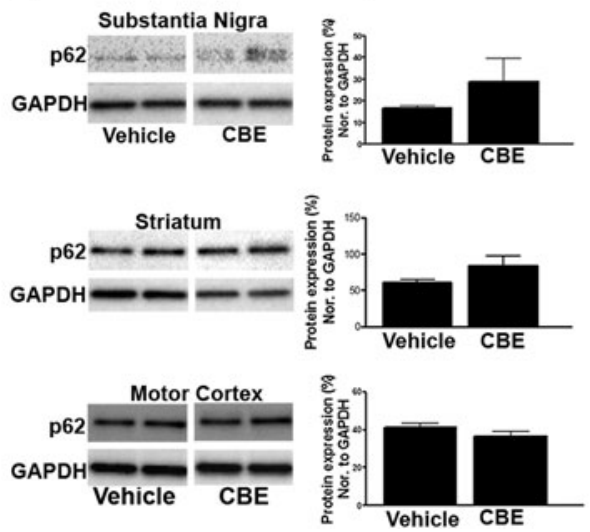

FIG. 6. GCase inhibition caused accumulation of proteinase-K-resistant insoluble $\alpha$-synuclein aggregates and induced autophagy-lysosomal proteins in the nigrostriatal pathway. Mice were treated with either vehicle or CBE and immunostained for insoluble $\alpha$-synuclein using a proteinase-K digestion protocol. $\alpha$-Synuclein insoluble aggregates were analyzed by size $\left(\mu \mathrm{m}^{2}\right)$ using NIH ImageJ. CBE caused a fivefold increase in the number of aggregates between 1 and $10 \mu \mathrm{m}^{2}(\mathbf{A})$. CBE also promoted the accumulation of the larger insoluble aggregates (between 11-20, 21-50, 51-100, and >151 $\mu \mathrm{m}^{2}$ ) (A). Western blots were performed using total cell lysate $(20-30 \mu \mathrm{g})$ from the substantia nigra and striatum. The chaperonemediated autophagy receptor, lysosomal-associated membrane protein (LAMP)-2A, was increased in the substantia nigra, striatum, and motor cortex of CBE-treated mice (B). The lipidated form of LC3 (LC3-II) was also increased in the substantia nigra, striatum, and motor cortex of CBE-treated mice (C). The lysosomal protease, cathepsin D (CSTD), was elevated in the substantia nigra, striatum, and motor cortex of CBE-treated mice (D). The ubiquitin-like protein, p62, remained unchanged in all three brain regions of CBE-treated mice $(\mathbf{E})$. ODs of the individual bands were quantified using NIH ImageJ and normalized to GAPDH on the same gel. ${ }^{*} p<0.05$, unpaired $t$-test. $n=4$ /group. Graphs are expressed as mean \pm SEM. 
A
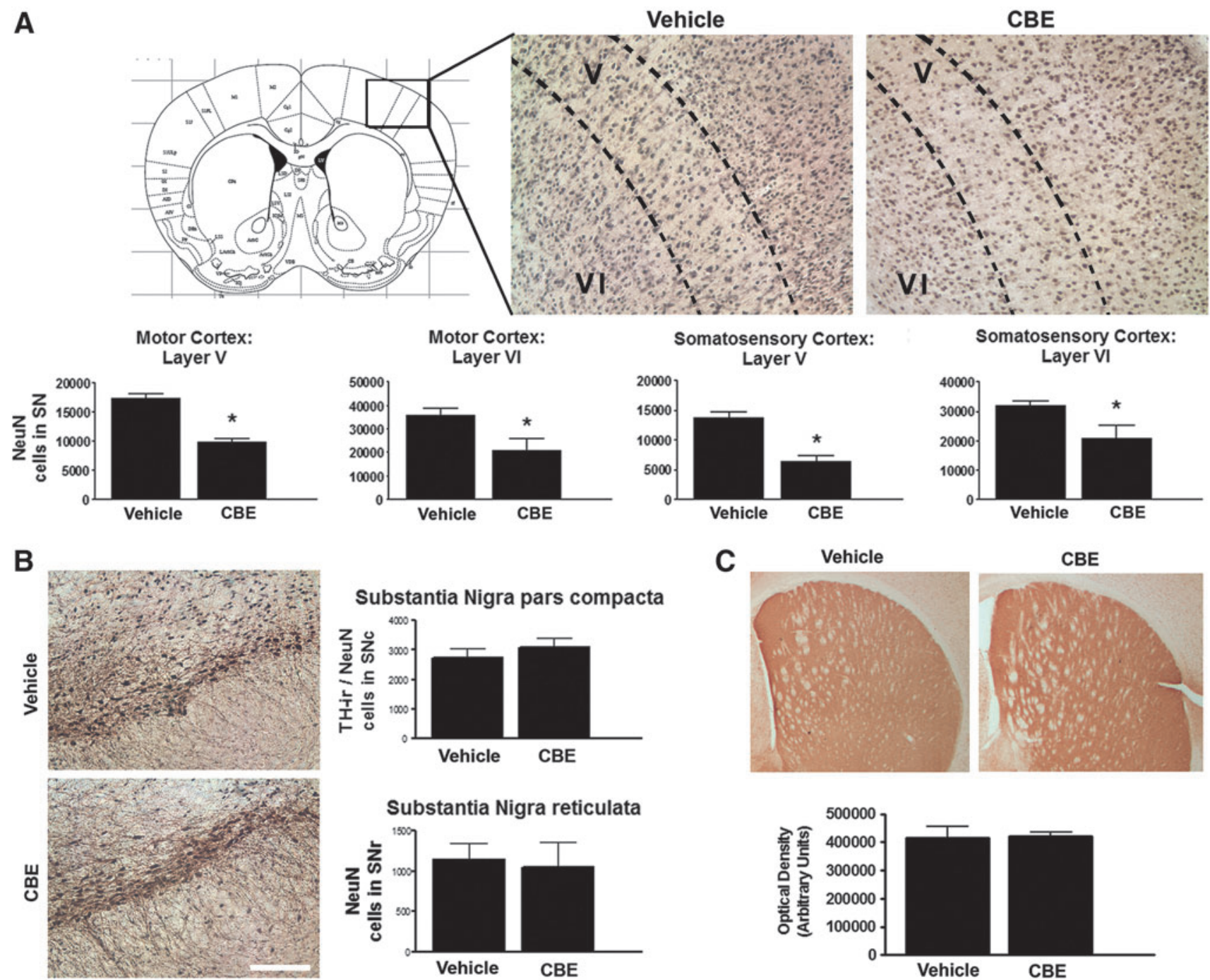

FIG. 7. GCase inhibition resulted in histopathological changes in mice. Stereological counts of neuronal cell bodies in cortical layers V and VI indicated that chronic (28 days) systemic treatment of CBE caused a reduction of NeuN-positive neurons (A). Stereological cell counts in the substantia nigra indicated that CBE did not alter the number of dopaminergic $(\mathrm{TH}+\mathrm{NeuN}$-labeled) neurons in the substantia nigra pars compacta or the number of NeuN-labeled neurons in the pars reticulata (B). There was also no effect of CBE treatment on dopaminergic striatal fiber density $(\mathbf{C}) * p<0.05$, unpaired $t$-test. $n=3-4$ /group. Graphs are expressed as mean \pm SEM.

cortex in comparison with vehicle-treated mice (Fig. 7A). The number of NeuN-positive cell bodies in the substantia nigra pars reticulata and tyrosine hydrolase $(\mathrm{TH}) / \mathrm{NeuN}$ positive neurons in the substantia nigra pars compacta were not altered following chronic CBE treatment (Fig. 7B). Similarly, optical density counts in the striatum revealed that chronic inhibition of GCase for 28 days did not affect the number of TH fibers in the striatum (Fig. 7C).

\section{Discussion}

A current challenge in $\alpha$-synucleinopathy research is determining what pathological events initiate the accumulation of toxic $\alpha$-synuclein oligomers and cause neurodegeneration. Our data provide clear evidence that systemic inhibition of lysosomal GCase causes several cellular changes throughout the brain that eventually lead to accumulation of $\alpha$-synuclein aggregates and region-specific predegenerative changes and neurodegeneration. CBE-induced inhibition of GCase caused accumulation of glycosphingolipids, widespread neuroinflammation, and altered levels of proteins involved in synaptic transmission and axonal transport. These changes were accompanied by deficits in lysosomal-autophagy degradation pathways, accumulation of $\alpha$-synuclein, and neurodegeneration. Our data indicate that massive inhibition of GCase by CBE causes disturbances in brain regions that are vulnerable in PD and related $\alpha$-synucleinopathies and provide insight into how age-related or genetic deficits in autophagy-lysosomal degradation systems may contribute to neurodegenerative diseases.

\section{GCase inhibition caused deficits in lysosomal degradation and accumulation of $\alpha$-synuclein}

High levels of glycosphingolipids in neurons can cause pathological accumulation of $\alpha$-synuclein oligomers (36), 
which may promote the onset and progression of PD. GCase is responsible for hydrolyzing GluCer in the lysosome, and under physiological conditions, GluCer maintains lysosomal function by modulating endolysosomal $\mathrm{pH}$ (55); therefore, changes in GluCer levels may disrupt normal lysosomal function and promote $\alpha$-synuclein aggregation. Our data clearly show that inhibition of GCase by CBE causes $\alpha$ synucleinopathy and neurodegeneration. The high levels of GluCer and GluSph either alone or in combination with the observed deficits in autophagy-lysosomal degradation may have caused the observed $\alpha$-synucleinopathy in the CBE model. High levels of GluCer can promote fibril formation of $\alpha$-synuclein and stabilize soluble oligomeric $\alpha$-synuclein (36). Similarly, inhibition of macroautophagy and CMA can also increase $\alpha$-synuclein levels $(44,64)$. Further studies will be required to determine whether reduced lysosomal GCase contributes to the pathophysiology of PD by promoting accumulation of $\alpha$-synuclein oligomers, either through a direct interaction between glycosphingolipids and $\alpha$-synuclein (36) or by disrupting autophagy-lysosomal degradation.

Both CMA and macroautophagy participate in degradation of $\alpha$-synuclein $(8,11,60,63)$. CMA is an inducible form of autophagy that uses heat shock cognate protein 70 (Hsc70) to transport proteins containing a specific consensus peptide sequence to LAMP-2A for lysosome degradation (10). We show that inhibition of GCase by CBE caused an increase in LAMP-2A, which may be an attempt to increase degradation of $\alpha$-synuclein and prevent cellular pathologies. A recent report demonstrated that LAMP-2A protein is reduced in the anterior cortex of early-stage PD patients, which is associated with a reduction in cholesterol and increased $\alpha$-synuclein (40). Our observed increase in LAMP-2A may therefore illustrate changes that occur during the prodromal stage of PD. Similar to other cellular systems, it is possible that CMA initially increases in an attempt to compensate for the accumulation of $\alpha$-synuclein. As the disease progresses with dopaminergic neuron degeneration and manifestation of clinical symptoms of PD, CMA may eventually become dysfunctional causing a decrease in LAMP-2A levels. Indeed, CMA can influence the survival of DA neurons, and overexpression of LAMP-2A prevents $\alpha$-synuclein-induced neurodegeneration (66). Moreover, cholesterol can regulate CMA by modulating LAMP-2A levels on the lysosomal membrane $(10,28)$, and normal cholesterol regulation is disrupted under conditions promoting high GluCer levels (56). Therefore, it is also possible that CBE-induced accumulation of GluCer and GluSph may cause the observed disruption of LAMP-2A levels.

LC3-II protein levels are elevated in the substantia nigra of PD patients and are likely caused by deficits in macroautophagy, given that LC3-II colocalizes with $\alpha$-synuclein within Lewy neurites and Lewy bodies (14). This increase in LC3-II has been replicated in transgenic mice that overexpress $\alpha$-synuclein and in neurons exposed to the mitochondrial complex 1 inhibitor, $\operatorname{MPP}^{+}(14,34)$. Our data showed that inhibition of GCase by CBE caused a significant increase in LC3-II protein levels in the striatum and substantia nigra. Elevated LC3-II protein levels occur upon induction of macroautophagy, where LC3-II initiates the formation of autophagosomes. However, high levels of LC3II may also suggest a deficit in autophagosome-lysosome fusion (27). Measuring protein levels of the Ub-like protein, SQSTM1/p62, is the most informative way to distinguish induction from deficits in macroautophagy (27) and our data indicated a trend toward increased levels of the Ub-like protein, SQSTM1/p62, following GCase inhibition by CBE. It is possible that SQSTM1/p62 levels may take longer to accumulate in comparison with LC3-II, and if SQSTM1/p62 levels had been measured at a later time point following $\mathrm{CBE}$ cessation, then the increase may have become significant. Nonetheless, our data suggest that inhibition of GCase disrupts macroautophagy, which may contribute to the accumulation of insoluble $\alpha$-synuclein aggregates.

In addition to the CMA and macroautophagy, our data also show that inhibition of GCase caused widespread elevation in cathepsin D levels. Increased cathepsin D levels may be upregulated in response to high levels of $\alpha$-synuclein in the lysosomes. Cathepsin D is a major lysosomal aspartyl protease and has been shown to be essential for the degradation of $\alpha$-synuclein $(12,24)$. Cathepsin D-deficient mice exhibit a progressive neurodegeneration that is accompanied by an accumulation of $\alpha$-synuclein oligomers (12).

Collectively, our data demonstrate that inhibition of lysosomal GCase resulted in intracellular changes that are reminiscent of PD. The observed accumulation of insoluble $\alpha$-synuclein may be caused by accumulation of GluCer and GluSph and/or a breakdown in autophagy-lysosomal degradation systems. Further studies will be required to elucidate the exact mechanism that is responsible for the CBE-induced accumulation of insoluble $\alpha$-synuclein aggregates.

\section{GCase inhibition induced widespread neuroinflammation and cortical degeneration}

We previously demonstrated that overexpression of mutant $\alpha$-synuclein causes progressive degeneration of the nigrostriatal dopamine neurons, which is preceded by microglial activation (9). Our current study shows that inhibition of GCase caused widespread microglia activation throughout the brain, which was accompanied by neurodegeneration in the motor and the somatosensory cortices, but not in the nigrostriatal pathway. It is possible that cortical neurons, are more sensitive to glycolipid accumulation following chronic CBE dosing in comparison with dopaminergic neurons' and thus degenerate faster. The systemic CBE dosing paradigm used in our study could be considered to be more of a model of neuronopathic Gaucher disease rather than sporadic PD because it causes a complete inhibition of GCase $(16,65)$. In comparison, nonGBA1-PD and Lewy body with dementia are clinically associated with a $\sim 30-50 \%$ reduction in brain GCase activity, and the clinical symptoms associated with the neurodegenerative changes manifest at a later age and are more gradual in comparison with those observed with neuronopathic Gaucher disease patients. Nonetheless, several of the pathological changes observed in the substantia nigra and striatum in mice treated with CBE in our current study are reminiscent of predegenerative changes that we have previously reported in a model of viral-induced $\alpha$-synucleinopathy (9). In that model of $\alpha$-synucleinopathy, altered levels of proteins related to axonal transport, the cytoskeleton, and synaptic function preceded degeneration of nigral dopaminergic neurons by at least 8 weeks and were accompanied by altered striatal dopamine homeostasis (15). It is possible that examination of 
CBE-treated mice at a later time point may have revealed nigrostriatal degeneration. This is further supported by recent data demonstrating that mice treated with a different, subchronic dosing regimen of CBE resulted in $\alpha$-synuclein accumulation and reduced striatal dopamine release (20), indicative of dysfunction in the nigrostriatal dopamine system. Transgenic Gaucher disease mice and wild-type (WT) mice treated with CBE caused progressive neuronal loss in the cerebrum and spinal cord 2 and 5 months after the final CBE injection, despite recovery of GCase levels (67). These data suggest that lysosomal deficits caused by inhibiting GCase may be sufficient to cause progressive degeneration in the nigrostriatal pathway reminiscent of $\mathrm{PD}$ pathology.

\section{GCase inhibition induced synaptic, axonal transport, and cytoskeletal protein changes in mice}

Efficient axonal transport is required to transport newly synthesized proteins and organelles to the synapse and, conversely, to remove damaged proteins and organelles destined for degradation. Our data showed that chronic treatment with $\mathrm{CBE}$ increased levels of the retrograde axonal transport proteins, dynein and dynactin, in the substantia nigra. Neurons predominantly rely on macroautophagy for protein and organelle turnover. Autophagosome biogenesis typically occurs distally at the axon tip and travels to the cell body using retrograde dynein-dynactin transport (33). Based on these data, we hypothesized that inhibition of lysosomal degradation by CBE may impair retrograde axonal transport and promote accumulation of $\alpha$-synuclein by preventing autophagosome transport from the synapse to the cell body. Indeed, mutations in dynactin can disrupt this heavily regulated axonal transport process and lead to neurodegeneration $(17,46)$. Mutations in DCTN1 impair dynactin-1 function and cause an atypical early-onset parkinsonism referred to as Perry Syndrome. These patients exhibit impaired microtubule binding, which is accompanied by severe dopaminergic neuron loss (2). Moreover, transgenic mice with a point mutation in the dynein heavy chain gene exhibit impaired retrograde axonal transport and motor and behavioral abnormalities, including hind limb clasping, loss of muscle tone, and incoordination, which is accompanied by striatal atrophy and dystrophic neurites (5). These studies support a role for dynactin and dynein in the pathogenesis of neurodegenerative disorders.

A disruption in $\alpha$ - and $\beta$-tubulin cytoskeletal protein levels in both the striatum and substantia nigra accompanied the observed changes in retrograde transport proteins. Impaired retrograde transport can prevent maturation of autophagosomes, which can be further impaired by high levels of synaptic $\alpha$-synuclein $(7,9)$. Oligomeric $\alpha$-synuclein can inhibit tubulin polymerization, disrupting proper axonal transport (7). Therefore, impaired transport mechanisms in the distal axon may lead to dystrophic neurites and accumulation of protein inclusions. Based on these data, CBE-induced abnormalities in $\alpha$-tubulin levels may promote $\alpha$-synuclein inclusion accumulation by disrupting proper retrograde and anterograde axonal transport along the cytoskeleton. Further studies will be required to determine whether the axonal transport and cytoskeletal changes are the cause or a consequence of the autophagy deficits and $\alpha$-synuclein inclusion accumulation.
In addition to the axonal transport and cytosketal changes, our data indicate that $\mathrm{CBE}$ caused changes to various proteins involved with synaptic function, including C1q, synaptotagmin, synaptophysin, and PSD-95. Evidence shows that synaptic dysfunction and loss precede degeneration of the cell soma and may be an early pathological event in several neurodegenerative diseases, including PD (9). $\alpha$-Synuclein is abundantly expressed in presynaptic terminals of dopamine neurons in the striatum and is necessary to maintain conformation and function of SNARE proteins (6). Impaired autophagy-lysosomal degradation of $\alpha$-synuclein that results in an accumulation of synaptic $\alpha$-synuclein will likely disrupt synaptic functioning. This is supported by data demonstrating that overexpression of $\alpha$-synuclein can disrupt neurotransmitter release by disrupting synaptic vesicle recycling before detectable neuropathology changes (41). Moreover, daily dosing of $\mathrm{CBE}$ to mice can disrupt dopamine neurotransmission by impairing striatal dopamine release and causing a reduction in postsynaptic density size (20). Synaptic accumulation of $\alpha$ synuclein is associated with redistribution of the synaptic SNARE proteins, SNAP-25, syntaxin-1, and synaptobrevin-2 (18). Collectively, these data provide new insights into the mechanisms underlying synaptic dysfunction, accumulation of $\alpha$-synuclein inclusions, and neuroinflammation in the pathophysiology of PD and related $\alpha$-synucleinopathies.

It is known that synapses are tagged during normal postnatal development by the classical complement pathway for normal synaptic pruning $(51,57)$. Microglial recruitment participates in the removal of unwanted and redundant synapses by upregulating the complement pathway $(4,57)$. C1q is the initiating protein of the complement pathway and is required for the phagocytosis of dead cells, debris, and pathogens. Recently, C1q and the complement pathway have also been implicated in synaptic removal during neurodegeneration (57). Our data clearly demonstrate that GCase inhibition induces widespread $\mathrm{Clq}$ expression, neuroinflammation, predegenerative changes in the nigrostriatal pathway, and neuronal loss in the cortex. Therefore, synapses and axons may be early targets of inflammation-induced neurodegeneration in the $\alpha$-synucleinopathies via the complement pathway.

\section{Conclusion}

The current article demonstrates that inhibition of GCase using a pharmacological inhibitor can induce the aggregation of $\alpha$-synuclein and disrupt autophagy-lysosomal degradation. Inhibition of GCase also resulted in widespread neuroinflammation, which was accompanied by complement activation and changes in synaptic and transport proteins. These changes were paralleled by neurodegeneration in the motor and somatosensory cortices. Collectively, these data validate the GBA and lysosomal pathways as therapeutic targets to reduce levels of aggregated $\alpha$-synuclein in PD.

\section{Materials and Methods}

\section{Animals}

Male BDF1 mice, 3-4 months of age, were used for all experimental procedures. Animals were housed in standard conditions in a 12-h dark/12-h light cycle, with ad libitum 
access to food and water. All animal procedures were performed in accordance with National Institutes of Health guidelines and were approved by the Institutional Animal Care and Use Committee (IACUC) at McLean Hospital, Harvard Medical School.

\section{Pharmacological inhibition of lysosomal GCase}

$\mathrm{CBE}$ is a selective irreversible inhibitor of lysosomal GCase activity and was purchased from EMD Millipore (Cat No. 234599). Mice received daily intraperitoneal (i.p.) injections, either CBE at $100 \mathrm{mg} / \mathrm{kg}$ or vehicle for 28 days, as previously described (59). Mice were euthanized at $24 \mathrm{~h}, 3$ days, 5 days, or 7 days following the final i.p. injection.

\section{GCase activity}

GCase activities were determined as previously described with slight modifications (50); mouse brain tissues $(\sim 5 \mathrm{mg})$ were homogenized in $300 \mu \mathrm{l}$ of water. Samples were diluted in a $2 \mathrm{mg} / \mathrm{ml}$ bovine serum albumin, citric acid sodium phosphate buffer (pH 5). Ten microliters of sample was added to $75 \mu$ of $10 \mathrm{~m} M$ 4-methylumbelliferyl- $\beta$-D-glucopyranoside (Sigma) substrate. After incubation with the substrate for $60 \mathrm{~min}$ at $37^{\circ} \mathrm{C}$, the reaction was terminated using $200 \mu \mathrm{l}$ of stop solution (0.3 $M$ glycine/ $0.2 M$ sodium carbonate, $\mathrm{pH} 10.7$ ). Plates were read (Ex 360/Em 460) in a Molecular Devices SPECTRAmax plate reader using Softmax Pro software. Enzymatic activity was assessed from a 4-methylumbelliferyl (Sigma) standard curve and normalized to protein content in each sample as determined using a bicinchoninic acid (BCA) assay (Thermo Scientific Pierce).

\section{Liquid chromatography-tandem mass spectrometry analysis of GlcCer and GluSph}

A $50 \mu \mathrm{l}$ aliquot of homogenate was used to prepare samples for the quantitation of GlcCer and GluSph. Eight hundred microliters of acetonitrile and methanol 1:1 solvent was used to extract GluCer and GluSph from the tissue. The samples were sonicated, vortexed, and centrifuged before the supernatant was transferred to an injection plate for liquid chromatography-tandem mass spectrometry (LC-MS/MS) analysis. For quantification of GlcCer, a $2 \mu \mathrm{l}$ sample was injected onto a Supelco $2.1 \mathrm{~mm}$ i.d. $\times 25 \mathrm{~cm}$ LC-Si HPLC column (Sigma) connected to a Shimadzu LC Prominence UFLC solvent delivery system. The elution was performed using isocratic elution from 6:10:920 (water:acetic acid:acetonitrile) that contains $6 \mathrm{~m} M$ ammonium formate at a flow rate of $500 \mu \mathrm{l} / \mathrm{min}$ for $17 \mathrm{~min}$. The column temperature was $45^{\circ} \mathrm{C}$. The eluent from the column was introduced into an Applied Biosystems QTrap 5500 triple quadrupole mass spectrometer operated in positive ion electrospray mode. GlcCer species (C16:0, C18:0, C20:0, C22:0, C24:0, C24:1, $\mathrm{C} 24: 0-\mathrm{OH})$ were identified by precursor ion scan for $\mathrm{m} / \mathrm{z} 264$, and $\mathrm{d} 3-\mathrm{C} 16$ was used as the internal standard for GlcCer analysis. Quantification of GlcCer was performed using the selective reaction monitoring (SRM). The GlcCer concentration was calculated from the combined peak area ratios of each of the seven molecular species. For quantitation of GluSph, the same LC-MS/MS system was used. The isocratic solvent system consisted of $0.08 \mathrm{ml} / \mathrm{min}$ mobile phase A (water) and $1.0 \mathrm{ml} / \mathrm{min}$ mobile phase $\mathrm{B}\left(\mathrm{CH}_{3} \mathrm{CN} / \mathrm{CH}_{3} \mathrm{OH} /\right.$
$\mathrm{CH}_{3} \mathrm{COOH}$ 97:2:1 with $5 \mathrm{mM}$ of ammonium formate). The SRM transitions monitored for GluSph and the internal standard plant GluSph were m/z 462 to $\mathrm{m} / \mathrm{z} 282$ and m/z 460 to $\mathrm{m} / \mathrm{z} 280$, respectively.

\section{Immunohistochemistry and antibodies}

Animals were terminally anesthetized with sodium pentobarbital and perfused transcardially with $25 \mathrm{ml}$ phosphatebuffered $0.9 \%$ saline (PBS), followed by $100 \mathrm{ml}$ of $4 \%$ paraformaldehyde in phosphate buffer. Brains were removed and postfixed in $4 \%$ paraformaldehyde for $4 \mathrm{~h}$ before placing them in $25 \%$ sucrose. Coronal sections were then cut, $40 \mu \mathrm{m}$ thick, on a freezing microtome and stored in antifreeze at $-20^{\circ} \mathrm{C}$ until use. For fluorescent microscopy, sections were blocked with $10 \%$ normal serum and incubated with antirabbit Iba1 (Wako; $1: 200$ ) at $4^{\circ} \mathrm{C}$ overnight, visualized with Alexa Fluor 568 (Invitrogen; 1:500), and mounted using Vecatshield (Vector Laboratories). Images were taken using a Zeiss LSM 510.

\section{Staining and quantification of insoluble $\alpha$-synuclein aggregates}

To visualize insoluble $\alpha$-synuclein aggregates, tissue sections were premounted on gelatin-coated slides and incubated with proteinase-K solution $(10 \mu \mathrm{g} / \mathrm{ml}$; Promega) for 20 $30 \mathrm{~min}$ at $37^{\circ} \mathrm{C}$. Endogenous peroxidases were quenched in $3 \%$ hydrogen peroxide for $7 \mathrm{~min}$ and placed in a blocking solution (Vectashield MOM kit) for $1 \mathrm{~h}$ at room temperature. Tissue sections were incubated with anti- $\alpha$-synuclein (1:1000; BD Transduction) overnight at $4^{\circ} \mathrm{C}$ using primary antibody diluent (Vectashield MOM kit). Sections were incubated with anti-mouse biotinylated secondary antibody (1:200) for $1 \mathrm{~h}$ at room temperature and visualized using a standard peroxidasebased method (Vectastain Elite, ABC kit; Vector Laboratories) and the chromogen, 3,3'-diaminobenzidine (Sigma). Insoluble $\alpha$-synuclein aggregates were quantified using the threshold function in ImageJ.

\section{Stereology}

To quantify the number of neurons in the substantia nigra and cortex, every $6^{\text {th }}$ brain section was collected. Freefloating tissue sections were rinsed in PBS before endogenous peroxidases were quenched in $3 \%$ hydrogen peroxide for $7 \mathrm{~min}$. After rinsing, the sections were incubated in $0.1 \%$ Triton X-100 in PBS containing 10\% normal serum. Tissue sections were then incubated with the primary antibodies, anti-rabbit TH (Pelfreeze; 1:300) and anti-mouse NeuN (Millipore; $1: 1000$ ), overnight at $4^{\circ} \mathrm{C}$. After washing in PBS, sections were incubated in biotinylated secondary antibody (1:200) and visualized using a standard peroxidase-based method (Vectastain Elite, ABC kit; Vector Laboratories), and the chromogen, 3,3'-diaminobenzidine (Sigma) and the substantia nigra sections were counterstained with Nissl. Unbiased stereology (StereoInvestigator 7; MFB Bioscience) was used to quantify neurons in the substantia nigra (compacta and reticulata) and cerebral cortex using the optical fractionator method at $20 \times$ magnification, using the following parameters: a $150 \times 150 \mu \mathrm{m}$ counting frame and $200 \times 200 \mu \mathrm{m}$ grid. All counts were performed blinded. Oneway ANOVA statistical analyses were performed, followed 
by the Bonferroni post hoc test. All analyses were conducted using GraphPad Prism (Version 5.0) (GraphPad Software, Inc.). Statistical significance was determined at the alpha level of 0.05 .

Optical density analysis of striatal TH-stained tissue sections was performed using ImageJ software (Version 1.46r) using images taken with a Zeiss Axioskop microscope and using the Spot RT color camera (Diagnostic Instruments, Inc.). Striatal images were taken at $2.5 \times$ magnification, $\sim+0.8$ (rostral) $\mathrm{mm}$ and -1.0 (caudal) relative to bregma in the anterior-posterior direction. Optical density values of inverted grayscale photomicrographs were then obtained for each image by drawing a contour around the rostral and caudal striatum (excluding the nucleus accumbens). Optical density values were first normalized to background levels by subtracting values of the corpus callosum. The level of $\mathrm{TH}$ fiber optical density was expressed as arbitrary units and presented as $\%$ of levels measured on the contralateral side.

All quantification was carried out in blind. Statistical analysis was performed using Prism software (version 5.0b). Either one-way ANOVA tests, with Dunnett's post hoc analysis, or T-tests were used.

\section{Western blotting}

Mice were terminally anesthetized and perfused transcardially with heparinized saline $(0.1 \%$ heparin in $0.9 \%$ saline), and brains were sliced at $750 \mu \mathrm{m}$ with the use of a tissue chopper. A previously published homogenization and Western blot protocol was followed (57). Membranes were incubated overnight at $4^{\circ} \mathrm{C}$ with the following primary antibodies: $\alpha$-tubulin (Upstate; 1:5000), $\beta$-tubulin (Chemicon; 1:5000), $\gamma$-tubulin (Sigma; 1:5000), kinesin-like protein (KIF)-2A (Abcam; 1:5000), KIF 17 (Abcam; 1:500), dynein (Santa Cruz; 1:250), dynactin (Santa Cruz; 1:1000), C1q (Abcam; 1:1000), synapsin (Thermo; 1:1000), synaptotagmin (BD Trans; 1:5000), synaptophysin (Santa Cruz; 1:500), SNAP-25 (Chemicon; 1:4000), PSD-95 (NeuroMab; 1:250), and glyceraldehyde-3-phosphate dehydrogenase (GAPDH; Millipore, 1:5000). Horseradish peroxidase-conjugated (HRP) goat anti-chicken, anti-rabbit, and anti-mouse secondary antibodies (all Jackson ImmunoResearch; 1:10,000) were used for Western blot detection. After washing in Tris-buffered salineTween, HRP-conjugated secondary antibodies were then applied for $1 \mathrm{~h}$ at room temperature. The blots were treated with ECL-Plus (Amersham Biosciences) and exposed using ChemiDoc ${ }^{\mathrm{TM}}$ XRS with image $\mathrm{Lab}^{\mathrm{TM}}$ software. Optical density analysis (NIH image) was used to determine the relative abundance of each protein of interest. Bands were normalized to GAPDH for that same sample and gel.

\section{Acknowledgments}

This work was supported by the Consolidated Anti-Aging Foundation, the Harvard Stem Cell Institute Translational Neuroscience Fund, the Poul Hansen family, the Harold and Ronna Cooper family, a fellowship from the Canadian Institute of Health Research (E.R.), and a grant from Shire Pharmaceuticals (O.I.).

\section{Author Disclosure Statement}

No competing financial interests exist.

\section{References}

1. Ahmed I, Liang Y, Schools S, Dawson VL, Dawson TM, and Savitt JM. Development and characterization of a new Parkinson's disease model resulting from impaired autophagy. J Neurosci 32: 16503-16509, 2012.

2. Aji BM, Medley G, O’Driscoll K, Larner AJ, and Alusi SH. Perry syndrome: a disorder to consider in the differential diagnosis of Parkinsonism. J Neurol Sci 330: 117-118, 2013.

3. Asselta R, Rimoldi V, Siri C, Cilia R, Guella I, Tesei S, Solda G, Pezzoli G, Duga S, and Goldwurm S. Glucocerebrosidase mutations in primary parkinsonism. Parkinsonism Relat Disord 20: 1215-1220, 2014.

4. Bialas AR and Stevens B. TGF-beta signaling regulates neuronal $\mathrm{Clq}$ expression and developmental synaptic refinement. Nat Neurosci 16: 1773-1782, 2013.

5. Braunstein KE, Eschbach J, Rona-Voros K, Soylu R, Mikrouli E, Larmet Y, Rene F, Gonzalez De Aguilar JL, Loeffler JP, Muller HP, Bucher S, Kaulisch T, Niessen HG, Tillmanns J, Fischer K, Schwalenstocker B, Kassubek J, Pichler B, Stiller D, Petersen A, Ludolph AC, and Dupuis L. A point mutation in the dynein heavy chain gene leads to striatal atrophy and compromises neurite outgrowth of striatal neurons. Hum Mol Genet 19: 4385-4398, 2010.

6. Chandra S, Gallardo G, Fernandez-Chacon R, Schluter OM, and Sudhof TC. Alpha-synuclein cooperates with CSPalpha in preventing neurodegeneration. Cell 123: 383 396, 2005.

7. Chen L, Jin J, Davis J, Zhou Y, Wang Y, Liu J, Lockhart PJ, and Zhang J. Oligomeric alpha-synuclein inhibits tubulin polymerization. Biochem Biophys Res Commun 356: 548-553, 2007.

8. Choubey V, Safiulina D, Vaarmann A, Cagalinec M, Wareski P, Kuum M, Zharkovsky A, and Kaasik A. Mutant A53T alpha-synuclein induces neuronal death by increasing mitochondrial autophagy. J Biol Chem 286: 10814-10824, 2011.

9. Chung CY, Koprich JB, Siddiqi H, and Isacson O. Dynamic changes in presynaptic and axonal transport proteins combined with striatal neuroinflammation precede dopaminergic neuronal loss in a rat model of AAV alpha-synucleinopathy. J Neurosci 29: 3365-3373, 2009.

10. Cuervo AM and Dice JF. A receptor for the selective uptake and degradation of proteins by lysosomes. Science 273: 501-503, 1996.

11. Cuervo AM, Stefanis L, Fredenburg R, Lansbury PT, and Sulzer D. Impaired degradation of mutant alpha-synuclein by chaperone-mediated autophagy. Science 305: 12921295, 2004.

12. Cullen V, Lindfors M, Ng J, Paetau A, Swinton E, Kolodziej P, Boston H, Saftig P, Woulfe J, Feany MB, Myllykangas L, Schlossmacher MG, and Tyynela J. Cathepsin $\mathrm{D}$ expression level affects alpha-synuclein processing, aggregation, and toxicity in vivo. Mol Brain 2: 5, 2009.

13. Decressac M, Mattsson B, Weikop P, Lundblad M, Jakobsson $\mathrm{J}$, and Bjorklund A. TFEB-mediated autophagy rescues midbrain dopamine neurons from alpha-synuclein toxicity. Proc Natl Acad Sci U S A 110: E1817-E1826, 2013.

14. Dehay B, Bove J, Rodriguez-Muela N, Perier C, Recasens A, Boya P, and Vila M. Pathogenic lysosomal depletion in Parkinson's disease. J Neurosci 30: 12535-12544, 2010.

15. Deleidi M, Hallett PJ, Koprich JB, Chung CY, and Isacson O. The Toll-like receptor-3 agonist polyinosinic:polycytidylic 
acid triggers nigrostriatal dopaminergic degeneration. $J$ Neurosci 30: 16091-16101, 2010.

16. Enquist IB, Lo Bianco C, Ooka A, Nilsson E, Mansson JE, Ehinger M, Richter J, Brady RO, Kirik D, and Karlsson S. Murine models of acute neuronopathic Gaucher disease. Proc Natl Acad Sci U S A 104: 17483-17488, 2007.

17. Farrer MJ, Hulihan MM, Kachergus JM, Dachsel JC, Stoessl AJ, Grantier LL, Calne S, Calne DB, Lechevalier B, Chapon F, Tsuboi Y, Yamada T, Gutmann L, Elibol B, Bhatia KP, Wider C, Vilarino-Guell C, Ross OA, Brown LA, Castanedes-Casey M, Dickson DW, and Wszolek ZK. DCTN1 mutations in Perry syndrome. Nat Genet 41: 163$165,2009$.

18. Garcia-Reitbock P, Anichtchik O, Bellucci A, Iovino M, Ballini C, Fineberg E, Ghetti B, Della Corte L, Spano P, Tofaris GK, Goedert M, and Spillantini MG. SNARE protein redistribution and synaptic failure in a transgenic mouse model of Parkinson's disease. Brain 133: 2032 2044, 2010.

19. Gegg ME, Burke D, Heales SJ, Cooper JM, Hardy J, Wood NW, and Schapira AH. Glucocerebrosidase deficiency in substantia nigra of parkinson disease brains. Ann Neurol 72: 455-463, 2012.

20. Ginns EI, Mak SK, Ko N, Karlgren J, Akbarian S, Chou VP, Guo Y, Lim A, Samuelsson S, LaMarca ML, VazquezDeRose J, and Manning-Bog AB. Neuroinflammation and alpha-synuclein accumulation in response to glucocerebrosidase deficiency are accompanied by synaptic dysfunction. Mol Genet Metab 111: 152-162, 2014.

21. Goker-Alpan O, Schiffmann R, LaMarca ME, Nussbaum RL, McInerney-Leo A, and Sidransky E. Parkinsonism among Gaucher disease carriers. J Med Genet 41: 937-940, 2004.

22. Grabowski GA. Gaucher disease and other storage disorders. Hematology Am Soc Hematol Educ Program 2012: 13-18, 2012.

23. Halperin A, Elstein D, and Zimran A. Increased incidence of Parkinson disease among relatives of patients with Gaucher disease. Blood Cells Mol Dis 36: 426-428, 2006.

24. Hasilik A and Neufeld EF. Biosynthesis of lysosomal enzymes in fibroblasts. Phosphorylation of mannose residues. J Biol Chem 255: 4946-4950, 1980.

25. Ho MW, Seck J, Schmidt D, Veath ML, Johnson W, Brady RO, and O'Brien JS. Adult Gaucher's disease: kindred studies and demonstration of a deficiency of acid betaglucosidase in cultured fibroblasts. Am J Hum Genet 24: 37-45, 1972.

26. Hruska KS, LaMarca ME, Scott CR, and Sidransky E. Gaucher disease: mutation and polymorphism spectrum in the glucocerebrosidase gene (GBA). Hum Mutat 29: 567583, 2008.

27. Klionsky DJ, Abdalla FC, Abeliovich H, Abraham RT, Acevedo-Arozena A, Adeli K, et al. Guidelines for the use and interpretation of assays for monitoring autophagy. Autophagy 8: 445-544, 2012.

28. Koga $\mathrm{H}$ and Cuervo AM. Chaperone-mediated autophagy dysfunction in the pathogenesis of neurodegeneration. Neurobiol Dis 43: 29-37, 2011.

29. Komatsu M, Kominami E, and Tanaka K. Autophagy and neurodegeneration. Autophagy 2: 315-317, 2006.

30. Kuma A, Hatano M, Matsui M, Yamamoto A, Nakaya H, Yoshimori T, Ohsumi Y, Tokuhisa T, and Mizushima N. The role of autophagy during the early neonatal starvation period. Nature 432: 1032-1036, 2004.
31. Lees AJ, Hardy J, and Revesz T. Parkinson's disease. Lancet 373: 2055-2066, 2009.

32. Machaczka M, Rucinska M, Skotnicki AB, and Jurczak W. Parkinson's syndrome preceding clinical manifestation of Gaucher's disease. Am J Hematol 61: 216-217, 1999.

33. Maday S, Wallace KE, and Holzbaur EL. Autophagosomes initiate distally and mature during transport toward the cell soma in primary neurons. J Cell Biol 196: 407-417, 2012.

34. Mak SK, McCormack AL, Manning-Bog AB, Cuervo AM, and Di Monte DA. Lysosomal degradation of alphasynuclein in vivo. J Biol Chem 285: 13621-13629, 2010.

35. Martinez-Vicente M, Sovak G, and Cuervo AM. Protein degradation and aging. Exp Gerontol 40: 622-633, 2005.

36. Mazzulli JR, Xu YH, Sun Y, Knight AL, McLean PJ, Caldwell GA, Sidransky E, Grabowski GA, and Krainc D. Gaucher disease glucocerebrosidase and alpha-synuclein form a bidirectional pathogenic loop in synucleinopathies. Cell 146: 37-52, 2011.

37. McCann H, Stevens CH, Cartwright H, and Halliday GM. alpha-Synucleinopathy phenotypes. Parkinsonism Relat Disord 20 Suppl 1: S62-S67, 2014.

38. McCormack AL, Mak SK, and Di Monte DA. Increased alpha-synuclein phosphorylation and nitration in the aging primate substantia nigra. Cell Death Dis 3: e315, 2012.

39. Montfort M, Chabas A, Vilageliu L, and Grinberg D. Functional analysis of 13 GBA mutant alleles identified in Gaucher disease patients: pathogenic changes and "modifier" polymorphisms. Hum Mutat 23: 567-575, 2004.

40. Murphy KE, Gysbers AM, Abbott SK, Tayebi N, Kim WS, Sidransky E, Cooper A, Garner B, and Halliday GM. Reduced glucocerebrosidase is associated with increased alpha-synuclein in sporadic Parkinson's disease. Brain 137: 834-848, 2014.

41. Nemani VM, Lu W, Berge V, Nakamura K, Onoa B, Lee MK, Chaudhry FA, Nicoll RA, and Edwards RH. Increased expression of alpha-synuclein reduces neurotransmitter release by inhibiting synaptic vesicle reclustering after endocytosis. Neuron 65: 66-79, 2010.

42. Neudorfer O, Giladi N, Elstein D, Abrahamov A, Turezkite T, Aghai E, Reches A, Bembi B, and Zimran A. Occurrence of Parkinson's syndrome in type I Gaucher disease. QJM 89: 691-694, 1996.

43. Neumann J, Bras J, Deas E, O'Sullivan SS, Parkkinen L, Lachmann RH, Li A, Holton J, Guerreiro R, Paudel R, Segarane B, Singleton A, Lees A, Hardy J, Houlden H, Revesz T, and Wood NW. Glucocerebrosidase mutations in clinical and pathologically proven Parkinson's disease. Brain 132: 1783-1794, 2009.

44. Orenstein SJ, Kuo SH, Tasset I, Arias E, Koga H, Fernandez-Carasa I, Cortes E, Honig LS, Dauer W, Consiglio A, Raya A, Sulzer D, and Cuervo AM. Interplay of LRRK2 with chaperone-mediated autophagy. Nat Neurosci 16: 394-406, 2013.

45. Osellame LD, Rahim AA, Hargreaves IP, Gegg ME, Richard-Londt A, Brandner S, Waddington SN, Schapira AH, and Duchen MR. Mitochondria and quality control defects in a mouse model of Gaucher disease-links to Parkinson's disease. Cell Metab 17: 941-953, 2013.

46. Puls I, Jonnakuty C, LaMonte BH, Holzbaur EL, Tokito M, Mann E, Floeter MK, Bidus K, Drayna D, Oh SJ, Brown RH, Jr., Ludlow CL, and Fischbeck KH. Mutant dynactin in motor neuron disease. Nat Genet 33: 455-456, 2003.

47. Rocha EM, Smith GA, Park E, Cao H, Brown EJ, Hallett PJ, and Isacson $\mathrm{O}$. Progressive decline of glucocerebrosidase in 
aging and Parkinson's disease. Ann Clin Transl Neurol 2: 433-438, 2015.

48. Sardi SP, Clarke J, Kinnecom C, Tamsett TJ, Li L, Stanek LM, Passini MA, Grabowski GA, Schlossmacher MG, Sidman RL, Cheng SH, and Shihabuddin LS. CNS expression of glucocerebrosidase corrects alpha-synuclein pathology and memory in a mouse model of Gaucherrelated synucleinopathy. Proc Natl Acad Sci U S A 108: 12101-12106, 2011.

49. Sardi SP, Clarke J, Viel C, Chan M, Tamsett TJ, Treleaven $\mathrm{CM}, \mathrm{Bu}$ J, Sweet L, Passini MA, Dodge JC, Yu WH, Sidman RL, Cheng SH, and Shihabuddin LS. Augmenting CNS glucocerebrosidase activity as a therapeutic strategy for parkinsonism and other Gaucher-related synucleinopathies. Proc Natl Acad Sci U S A 110: 3537-3542, 2013.

50. Sardiello M, Palmieri M, di Ronza A, Medina DL, Valenza M, Gennarino VA, Di Malta C, Donaudy F, Embrione V, Polishchuk RS, Banfi S, Parenti G, Cattaneo E, and Ballabio A. A gene network regulating lysosomal biogenesis and function. Science 325: 473-477, 2009.

51. Schafer DP, Lehrman EK, Kautzman AG, Koyama R, Mardinly AR, Yamasaki R, Ransohoff RM, Greenberg ME, Barres BA, and Stevens B. Microglia sculpt postnatal neural circuits in an activity and complement-dependent manner. Neuron 74: 691-705, 2012.

52. Settembre $C$ and Ballabio A. TFEB regulates autophagy: an integrated coordination of cellular degradation and recycling processes. Autophagy 7: 1379-1381, 2011.

53. Sidransky E and Lopez G. The link between the GBA gene and parkinsonism. Lancet Neurol 11: 986-998, 2012.

54. Sidransky E, Nalls MA, Aasly JO, Aharon-Peretz J, Annesi G, Barbosa ER, Bar-Shira A, Berg D, Bras J, Brice A, Chen CM, Clark LN, Condroyer C, De Marco EV, Durr A, Eblan MJ, Fahn S, Farrer MJ, Fung HC, Gan-Or Z, Gasser T, Gershoni-Baruch R, Giladi N, Griffith A, Gurevich T, Januario C, Kropp P, Lang AE, Lee-Chen GJ, Lesage S, Marder K, Mata IF, Mirelman A, Mitsui J, Mizuta I, Nicoletti G, Oliveira C, Ottman R, Orr-Urtreger A, Pereira LV, Quattrone A, Rogaeva E, Rolfs A, Rosenbaum H, Rozenberg R, Samii A, Samaddar T, Schulte C, Sharma M, Singleton A, Spitz M, Tan EK, Tayebi N, Toda T, Troiano AR, Tsuji S, Wittstock M, Wolfsberg TG, Wu YR, Zabetian CP, Zhao Y, and Ziegler SG. Multicenter analysis of glucocerebrosidase mutations in Parkinson's disease. $N$ Engl J Med 361: 1651-1661, 2009.

55. Sillence DJ. Glucosylceramide modulates endolysosomal pH in Gaucher disease. Mol Genet Metab 109: 194-200, 2013.

56. Sillence DJ, Puri V, Marks DL, Butters TD, Dwek RA, Pagano RE, and Platt FM. Glucosylceramide modulates membrane traffic along the endocytic pathway. J Lipid Res 43: 1837-1845, 2002.

57. Stevens B, Allen NJ, Vazquez LE, Howell GR, Christopherson KS, Nouri N, Micheva KD, Mehalow AK, Huberman AD, Stafford B, Sher A, Litke AM, Lambris JD, Smith SJ, John SW, and Barres BA. The classical complement cascade mediates CNS synapse elimination. Cell 131: 1164-1178, 2007.

58. Tayebi N, Callahan M, Madike V, Stubblefield BK, Orvisky E, Krasnewich D, Fillano JJ, and Sidransky E. Gaucher disease and parkinsonism: a phenotypic and genotypic characterization. Mol Genet Metab 73: 313-321, 2001.

59. Tayebi N, Walker J, Stubblefield B, Orvisky E, LaMarca ME, Wong K, Rosenbaum H, Schiffmann R, Bembi B, and
Sidransky E. Gaucher disease with parkinsonian manifestations: does glucocerebrosidase deficiency contribute to a vulnerability to parkinsonism? Mol Genet Metab 79: 104109, 2003.

60. Tofaris GK, Kim HT, Hourez R, Jung JW, Kim KP, and Goldberg AL. Ubiquitin ligase Nedd4 promotes alphasynuclein degradation by the endosomal-lysosomal pathway. Proc Natl Acad Sci U S A 108: 17004-17009, 2011.

61. Tsuang D, Leverenz JB, Lopez OL, Hamilton RL, Bennett DA, Schneider JA, Buchman AS, Larson EB, Crane PK, Kaye JA, Kramer P, Woltjer R, Kukull W, Nelson PT, Jicha GA, Neltner JH, Galasko D, Masliah E, Trojanowski JQ, Schellenberg GD, Yearout D, Huston H, Fritts-Penniman A, Mata IF, Wan JY, Edwards KL, Montine TJ, and Zabetian CP. GBA mutations increase risk for Lewy body disease with and without Alzheimer disease pathology. Neurology 79: 1944-1950, 2012.

62. Turner BM and Hirschhorn K. Properties of beta-glucosidase in cultured skin fibroblasts from controls and patients with Gaucher disease. Am J Hum Genet 30: 346-358, 1978.

63. Watanabe Y, Tatebe H, Taguchi K, Endo Y, Tokuda T, Mizuno T, Nakagawa M, and Tanaka M. p62/SQSTM1dependent autophagy of Lewy body-like alpha-synuclein inclusions. PLoS One 7: e52868, 2012.

64. Winslow AR, Chen CW, Corrochano S, Acevedo-Arozena A, Gordon DE, Peden AA, Lichtenberg M, Menzies FM, Ravikumar B, Imarisio S, Brown S, O'Kane CJ, and Rubinsztein DC. alpha-Synuclein impairs macroautophagy: implications for Parkinson's disease. J Cell Biol 190: 10231037, 2010.

65. Wong K, Sidransky E, Verma A, Mixon T, Sandberg GD, Wakefield LK, Morrison A, Lwin A, Colegial C, Allman JM, and Schiffmann R. Neuropathology provides clues to the pathophysiology of Gaucher disease. Mol Genet Metab 82: 192-207, 2004.

66. Xilouri M, Brekk OR, Kirik D, and Stefanis L. LAMP2A as a therapeutic target in Parkinson disease. Autophagy 9: 2166-2168, 2013.

67. Xu YH, Reboulet R, Quinn B, Huelsken J, Witte D, and Grabowski GA. Dependence of reversibility and progression of mouse neuronopathic Gaucher disease on acid betaglucosidase residual activity levels. Mol Genet Metab 94: 190-203, 2008.

Address correspondence to: Dr. Ole Isacson Neuroregeneration Research Institute Harvard Medical School/McLean Hospital Belmont, MA 02478

E-mail: isacson@hms.harvard.edu

Dr. Penelope J. Hallett Neuroregeneration Research Institute Harvard Medical School/McLean Hospital Belmont, MA 02478

E-mail: phallett@mclean.harvard.edu

Date of first submission to ARS Central, February 24, 2015; date of final revised submission, May 29, 2015; date of acceptance, June 18, 2015. 


\section{Abbreviations Used}

$\mathrm{BCA}=$ bicinchoninic acid

$\mathrm{CBE}=$ conduritol- $\beta$-epoxide

$\mathrm{CMA}=$ chaperone-mediated autophagy

GAPDH $=$ glyceraldehyde-3-phosphate dehydrogenase

GCase $=$ glucocerebrosidase

GluCer $=$ glucosylceramide

GluSph $=$ glucosylsphingosine

$\mathrm{HRP}=$ horseradish peroxidase

i.p. $=$ intraperitoneal

$\mathrm{KIF}=$ kinesin-like protein

LAMP $=$ lysosomal-associated membrane protein
LC3 = microtubule-associated protein 1A/1B-light chain 3

LC-MS/MS = liquid chromatography-tandem mass spectrometry

$\mathrm{OD}=$ optical density

PBS $=$ phosphate-buffered saline

$\mathrm{PD}=$ Parkinson's disease

PSD-95 = postsynaptic density protein 95

SNAP-25 = synaptosomal-associated protein 25

$\mathrm{SRM}=$ selective reaction monitoring

TFEB $=$ transcription factor EB

$\mathrm{TH}=$ tyrosine hydrolase

$\mathrm{WT}=$ wild-type 